REVISTA DE DERECHO UNED, NÚM. 27, 2021

\title{
RESPONSABILIDAD SOCIAL Y SOSTENIBILIDAD CORPORATIVAS: HACIA UNA NECESARIA Y URGENTE SUPERACIÓN DE AMBOS CONCEPTOS ${ }^{1}$
}

\author{
CORPORATE SOCIAL RESPONSIBILITY (CSR) AND CORPORATE \\ SOCIAL SUSTAINIBILITY (CSS): TOWARDS A NECCESARY AND \\ URGENT OVERCOMING OF BOTHS CONCEPTS
}

\author{
Miguel-Angel Luelmo MilláN \\ Ex Magistrado del Tribunal Supremo \\ Ex Profesor Doctor Asociado de la UNED \\ A mis padres, $M^{a}$ Luisa y Enrique (+). \\ A mis nietecitos, Nicolás (5), Eduardo (3) y Beltrán (1).
}

Sumario: I. Introducción II. Responsabilidad Social Coroporativa (RSC): su traducción oficial y su origen en la buena fe (bona fides) III. Nivel internacional y supranacional. IV. Negociación Colectiva y Derecho necesario. V. Sostenibilidad. VI. Conclusiones.

Resumen: Desde su implantación, el concepto RSC ha sufrido una rápida evolución y, conservando su base, se amplía a medida que el mundo demanda un mayor campo de actuación porque la filosofía intrínseca de ese concepto y sus afines se revela como la más

1 Como textos generales en la materia pueden citarse: Sánchez García V. E.; Cano Linares, $M^{\mathrm{a}}$ A., Peribáñez Blasco, "Responsabilidad social corporativa. El papel de las Naciones Unidas y otras organizaciones internacionales en la promoción de la RSC”, Edit. Dykinson SL, 2017.

Y la muy reciente "Responsabilidad Social Corporativa. Nuevos retos, nuevas soluciones". Dir. Boldó Roda, C.; Edit. Universitat Jaume I (UJI), Col. Estudis Juridics; Castellón, 2021.

2 "Homo sum; humani nihil a me alienum est puto" ("soy un ser humano; nada humano me es ajeno". Terencio, Heautontimorumenos.

(C) UNED. Revista de Derecho UNED, núm. 27, 2021 
idónea para luchar contra el peligro ya inmediato que la sociedad global y su medio ambiente están corriendo, que, de no comenzar a detenerlo con eficacia y rapidez, llevará pronto a la extinción de la vida en sus diversas manifestaciones. Por eso se habla hace algún tiempo ya de SSC y, de ahí se marcha a una simbiosis de ambos términos que nos lleve, simplemente, a sostenibilidad en todas sus manifestaciones, si es que aún hay tiempo. Pero los daños que ha causado las viejas fuentes de energía de un lado y la nueva tecnología al alcance de cualquiera, un avance desbocado de las telecomunicaciones y la propia globalización en su aspecto más negativo de otro, sólo un gran cambio a todos los niveles en los principios, los valores, las normas y los métodos de los seres humanos, acordado y coordinado en un marco jurídico nacional, internacional y supranacional podrá conjurarlos.

Palabras clave: responsabilidad; sostenibilidad; buena fe; medio ambiente; clima; supervivencia

Abstract: Since its implementation, the CSR concept has undergone rapid evolution and, while maintaining its base, it expands as the world demands a greater field of action because the intrinsic philosophy of this concept and its related ones is revealed as the most suitable to fight against the already immediate danger that global society and its environment are running, which, if we do not begin to stop it effectively and quickly, will soon lead to the extinction of life in its various manifestations. For this reason, there has been talk of SSC for some time and, from there, a symbiosis of both terms leads us, simply, to sustainability in all its manifestations, if there is still time. But the damage caused by old energy sources on the one hand and news technologys availables to anyone, a runaway advance in telecommunications and globalization itself in its most negative aspect on the other, just a great change at all levels in principles, values, standards and methods of human beings, agreed and coordinated in a national, international and supranational legal framework will be able to avert them.

Key words: responsibility; sustainability; good faith; environment; climate; survival.

Recepción original: 27-3-2020

Aceptación original: 30-6-2020 


\section{INTRODUCCIÓN}

El mundo tiene la dimensión de cada uno de los seres humanos que lo habitan y éstos deben su existencia y están supeditados a su medio natural, de tal manera que se crea una perfecta interdependencia y una simbiosis entre uno y otros cuya fragilidad es el mayor riesgo para la garantía de un futuro -siempre contingente- en el escenario multiversal.

El espacio planetario ha reducido su importancia de un modo más que notable, constituyendo un factor decididamente a la baja a medida que se desarrollan las comunicaciones en particular y la tecnología en general, cuyo crecimiento es constante y exponencial, careciendo aquéllas ya de fronteras e incidiendo, todo ello, en la concepción de un hábitat global en el que la medida es éste en su conjunto, porque no hay nada que no se conozca e influya desde el momento mismo en que se produce.

Y ahí radica el marco de lo que ha dado en llamar globalización, concepto referencial en todos los ámbitos y materias, aunque de significado ambigüo. Todo nos afecta a todos más o menos directamente, se puede decir ahora más que nunca desde que comenzó la historia de la humanidad, lo que ya había quedado reflejado sabiamente en tiempos antiguos, y tiene una traducción política, social (en cualquiera de sus facetas, como, entre otras, la sanitaria), económica y ambiental a cualquier nivel y en cualquier distancia, lo que genera necesariamente la responsabilidad de cada uno y una responsabilidad colectiva, tanto por áreas como general.

En este contexto, fruto de la evolución humana, con tantas luces como sombras, se hace necesaria constantemente la acuñación de nuevos términos para definir conceptos de aspectos más o menos inéditos en su conjunto, aunque en su versión más restringida y primitiva lleven mucho tiempo entre nosotros.

Siempre se ha distinguido la persona y la entidad responsable de la que no lo es, con la consiguiente y lógica diferencia de otorgarle generalmente confianza a la primera y negársela a la segunda, o lo que es lo mismo, de conceder o negar, en lo posible, un trato fluido y bidireccional en beneficio de todas las partes o en su perjuicio, que, en este último caso y cuanto menos, el interesado/a tratará, si todavía puede, de evitar o minimizar de futuro eludiendo relaciones por venir.

Pero esas relaciones son necesarias en su conjunto porque constituyen la filosofía misma de la vida y aspectos sustanciales de ella, 
como la economía, que se erige en uno de los motores de la maquinaria ideada por el ser humano para, como está escrito en su ADN, continuar progresando y abriendo caminos nuevos.

\section{RESPONSABILIDAD SOCIAL COROPORATIVA (RSC) : SU TRADUCCIÓN OFICIAL Y SU ORIGEN EN LA BUENA FE (BONA FIDES)}

Sobre esta base y aunque la expresión "responsabilidad social corporativa" data de los años cincuenta del pasado siglo en los Estados Unidos, cobra carta de naturaleza en Europa en los años 90 y ha sido desde entonces objeto de un tratamiento intensivo y abundante tanto a nivel normativo como doctrinal y en los medios.

El Diccionario del Español Jurídico $(2016)^{1}$ da una definición general del concepto diciendo que se trata de un "apoyo, generalmente económico, dispensado por parte de las empresas a causas y organizaciones de interés general con el objetivo de mejorar la imagen de las primeras", añadiendo una versión mercantil ( $2^{\mathrm{a}}$ acepción) como "integración voluntaria por las empresas de los distintos intereses afectados por su actividad en sus operaciones mercantiles y sus relaciones con terceros". En idénticos términos para una y otra se expresa el Diccionario Panhispánico del Español Jurídico (2020).

De todo ello parece deducirse, en una primera impresión, una visión del concepto limitada al marketing empresarial por lo que respecta a su acepción general y una más concreta que tiene en cuenta los intereses de los diferentes stakeholders y de los terceros en el ámbito operacional de la empresa, al evidente objeto de facilitar las relaciones con los mismos y con la clientela en general y así, una mayor y más positiva resultancia del beneficio.

En ambas, pues, lo que caracteriza a la descripción es el objetivo último crematístico que se pretende alcanzar, que descarta cualquier aproximación a una idea exclusivamente filantrópica o altruista o incluso social, por otra parte ajena, en principio, al fin idisosincrático empresarial inmanente en la idea de economía de mercado, que se reconoce como marco del principio de la libertad de empresa recogido en el art 38 de la Constitución Española, con el que se encomienda a los poderes públicos la garantía y protección de su ejercicio, "de acuerdo con las exigencias de la economía general".

1 Diccionario del Español Jurídico, Dir. Santiago Muñoz Machado; Real Academia Española y Consejo General del Poder Judicial; Espasa Libros S.L.U. 2016 
Economía libre, por tanto, atenta al momento y al mercado, que, a su vez, son consecuencia de la filosofía imperante en la sociedad de un determinado período histórico, la cual, en nuestros tiempos, es, más que nunca hasta ahora, la que rige a nivel internacional o, cuanto menos, en el área de nuestra cultura occidental.

Sin embargo, en una esfera más concreta como es la estrictamente jurídica, las definiciones no se compadecen del todo con las expresadas y así, aunque también en el mismo marco económico, el art 39 de la Ley 2/2011, de 4 de marzo, de Economía Sostenible, señala en sus dos primeros números que "con el objetivo de incentivar a las empresas, organizaciones e instituciones públicas o privadas, especialmente a las pequeñas y medianas y a las empresas individuales, a incorporar o desarrollar politicas de responsabilidad social, las Administraciones Públicas mantendrán una política de promoción de la responsabilidad social, difundiendo su conocimiento y las mejores prácticas existentes y estimulando el estudio y análisis sobre los efectos en materia de competitividad empresarial de las politicas de responsabilidad social.

En particular, el Gobierno pondrá a su disposición un conjunto de características e indicadores para su autoevaluación en materia de responsabilidad social, así como modelos o referencias de reporte, todo ello de acuerdo con los estándares internacionales en la materia.

El conjunto de características, indicadores y modelos de referencia deberá atender especialmente a los objetivos de transparencia en la gestión, buen gobierno corporativo, compromiso con lo local y el medioambiente, respeto a los derechos humanos, mejora de las relaciones laborales, promoción de la integración de la mujer, de la igualdad efectiva entre mujeres y hombres, de la igualdad de oportunidades y accesibilidad universal de las personas con discapacidad y del consumo sostenible, todo ello de acuerdo con las recomendaciones que, en este sentido, haga el Consejo Estatal de la Responsabilidad Social Empresarial, constituido por el Real Decreto 221/2008, de 15 de febrero, por el que se regula el Consejo Estatal de Responsabilidad Social de las Empresas".

Se trata, según la dicción literal del texto referido, de "incentivar" y no sólo a las empresas sino también a organizaciones e instituciones públicas y privadas a abrazar el concepto de responsabilidad social para, entre otros fines, hacerlos más competitivas y con ello, más eficaces y mejores, en lo que vendría a resultar finalmente una especie de proceso de selección natural por el que quedarían tan solo los más aptos global y socialmente considerados. 
Se diseñan, en consecuencia y aunque todavía en un marco para la economía, unos objetivos amplios y pormenorizados que trascienden del mismo dentro aún del contexto empresarial, porque es lo que se quiere que sea la empresa hoy y en el futuro, abandonando esquemas y planteamientos anteriores y más reducidos socialmente. El respeto a los derechos humanos, la plena integración de la mujer y su igualdad efectiva con el hombre, la igualdad de oportunidades y la accesibilidad universal de las personas discapacitadas a los que se alude en el precepto conforman un escenario mucho más humano, a lo que se añade cuanto de referencia se hace también al respeto al medio ambiente y al consumo racional y en armonía con el mismo. Y todo ello sea o no rentable a corto plazo, aunque es evidente que lo será porque así lo quiere la sociedad, en la que se integran, inevitablemente, esos consumidores, es decir, los destinatarios en última instancia de la producción, o lo que es lo mismo, los clientes.

De todo ello parece deducirse que inicialmente la RSC ha sido concebida como una moderna expresión de capitalismo humanista e incluso como una nueva manifestación de filantropía o altruismo aplicado, pero, según se verá, la idea, al menos actualmente, trasciende a todo ello y va ampliando su contorno mucho más allá hasta generar, cada vez más, una filosofía con perspectiva de política mundial para la mejora y progreso de las relaciones humanas en su dimensión más personal y para la misma supervivencia, con incorporación constante de nuevo conceptos y disciplinas como economía circular, corporate compliance, green \& tech o nuevas metodologías como el transformative learning.

En el estricto ámbito jurídico, esa filosofía tiene en gran manera su base o su conexión con el fundamental valor del ordenamiento en general sin el cual éste no se entiende: el superprincipio de buena fe, presente en todo el Derecho material y en el procesal ${ }^{2}$, como pauta de conducta en las relaciones tanto individuales como sociales en general e incluso en el marco de cualquier desavenencia o confrontación como es el segundo, de tal modo que la ausencia de aquél vía mala fe, abuso de derecho, fraude de ley, temeridad, etc, que son sus términos antitéticos, merece no sólo la inmediata reprobación colectiva sino incluso su castigo.

La buena fe es un principio ético, metajurídico, que integra ya el Derecho Romano revestido de la mayor importancia ("bona fides"),

2 Luelmo Millán, Miguel-Angel, "La buena fe en el orden jurisdiccional social: exégesis normativa de un concepto infrapercibido". Revista Laboral y Seguridad Social Sepin, Diciembre 2019 (1 ${ }^{\mathrm{a}}$ parte), $\mathrm{N}^{\mathrm{o}} 7$ y Marzo $2020\left(2^{\mathrm{a}}\right.$ parte) $\mathrm{N}^{\mathrm{o}} 8$. 
y que busca modernamente, por encima de todo, el trato digno y considerado en un contexto de honradez, transparencia, diligencia, equilibrio y respeto, sin perjuicio de intereses encontrados, partiendo de la idea de igualdad -en su más amplia acepción- entre los ciudadanos por el mero hecho de serlo (con su límite natural en las situaciones de desigualdad plenamente justificadas), e intentando, por encima de todo, ubicarla allí donde no se halla presente, en tanto en cuanto constituye un derecho fundamental del individuo (art 1 de la Declaración Universal de los Derechos Humanos, DUDH, y 14 de la CE).

Nada tiene que ver este concepto de buena fe, pues, con lo que se ha dado en llamar "buenismo", definido por la RAE como "actitud de quien ante los conflictos rebaja su gravedad, cede con benevolencia o actúa con excesiva tolerancia" y también, quizás de modo más exacto y preciso, en el diccionario Oxford Languages como "actitud política y social que consiste en defender los mejores valores de las relaciones humanas, como la tolerancia y la solidaridad, e ignorar sus aspectos negativos de forma poco pragmática". La buena fe es crítica con los postulados contrarios ya citados, que son sus transgresores, y en tal condición se persiguen y sancionan desde la misma plataforma jurídica, de manera que es, ante todo, un concepto dinámico, a pesar de su naturaleza ética, en tanto en cuanto supone también tener en cuenta los límites, de manera que ni se cede ni se abonan principios ni soluciones maximalistas.

\section{NIVEL INTERNACIONAL Y SUPRANACIONAL}

A partir de lo ya dicho, la RSE (RS empresarial) y RSC (RS corporativa) e incluso RSO (RS de las organizaciones) va más allá e incorpora también el principio-idea de necesidad, aunque sorprendentemente todavía y desde su origen en el estricto marco de la voluntariedad llamado a corregirse o matizarse, al menos un tanto, en beneficio de la sociedad, aunque quizás para ello haya de desplazarse en igual grado o manera hacia el concepto de la sostenibilidad social. Necesidad de alcanzar globalmente un comportamiento más digno y justo en las relaciones individuales, empresariales y sociales así como de llegar a acuerdos y contar con instrumentos de protección de la salud y del medio ambiente para preservar la vida y su marco de desarrollo, tan seriamente amenazados, cuanto menos, a medio y largo plazo como consecuencia de una visión egoísta y de un desarrollo incontrolado y de la más alta toxicidad que supone para la supervivencia del género humano y de todas las formas de vida, seriamente amenazadas desde hace tiempo. 
Sobre la base precitada, la RSC tiene un previo marco en el ámbito inter y supranacional que sirve de referencia u orienta el de los diferentes países y, en definitiva, de los propios seres humanos como individuos y como colectivos.

Y así, la ORGANIZACIÓN DE NACIONES UNIDAS (ONU) había definido ya en 1999 tanto unos "principios", en número de 10, y unos "objetivos" (17) en su Global Compact, o Pacto Global o Mundial anunciado por su Secretario General en el Foro de Davos (Foro Económico Mundial) en su reunión de ese año en lo que se ha dado en decir que constituye la mayor iniciativa mundial de RSE con el fin de " incorporar los 10 Principios en las actividades empresariales de todo el mundo (y) canalizar acciones en apoyo de los objetivos más amplios de las Naciones Unidas, incluidos los Objetivos de Desarrollo Sostenible (ODS)"3. En septiembre de 2015 se aprobó por parte de la Asamblea General de Naciones Unidas, la Agenda 2030 para el Desarrollo Sostenible y con ella, los mencionados Objetivos (ODS), que constituyen, según la misma, una llamada mundial para adoptar medidas que logren acabar con los grandes problemas del planeta; poner fin a la pobreza y a la desigualdad, alcanzar la igualdad de género y el acceso para todos a un trabajo digno, facilitar el acceso a servicios de salud y a una educación adecuada, proteger el medioambiente ${ }^{4}$ y garantizar que todas las personas disfruten de paz y prosperidad.

Los ODS son el nuevo marco principal de contribución al desarrollo sostenible, compuesto por 17 Objetivos y 169 Metas asociadas,

3 Sobre el particular y para detalle de unos y otros puede verse, Luelmo Millán, Miguel-Angel, "La responsabilidad social corporativa en el ámbito del Derecho Laboral. Un instrumento económico-jurídico para un humanismo del siglo XXI", págs 243 y ss, Edit. Netbiblo, 2012

4 Para hacer frente al cambio climático como una amenaza al medio ambiente y al desarrollo sostenible se adoptó el Acuerdo de París (tratado internacional jurídicamente vinculante) adoptado el 12 de diciembre de 2015 y firmado el 22 de abril de 2016 en Nueva York por 196 países dentro de la Convención Marco de las Naciones Unidas sobre el Cambio Climático (UNFCCC, por sus siglas en inglés), que establece medidas para la reducción de las emisiones de gases de efecto invernadero.

Acerca de este punto, la última y más que inquietante, desoladora noticia de la referida Convención ha sido dar a conocer el 26/02/21 su "Informe de Síntesis de los Compromisos Nacionales de Reducción de emisiones" (NDC, por sus siglas en inglés) que muestra que sólo 75 países han elevado sus compromisos por el cambio climático, con lo que los niveles actuales en tal sentido están "muy lejos" de situarse en el camino con el que se pueden alcanzar los objetivos del Acuerdo del Clima de París. Por ello reclama a los países que redoblen sus esfuerzos y aumenten su compromiso nacional de contribución a la lucha contra el cambio climático en 2021 si quieren cumplir con los objetivos del Acuerdo. madridpress.com, 27/02/21. 
lanzados oficialmente en enero de 2016 que deben cumplirse antes del referido 2030, estando dirigida la Agenda a todos los agentes del planeta: los gobiernos, las empresas y sociedad civil.

Oficialmente se ha declarado que la Agenda 2030 para el Desarrollo Sostenible representa el compromiso internacional para hacer frente a los retos sociales, económicos y medioambientales de la globalización, poniendo en el centro a las personas, el planeta, la prosperidad y la paz, bajo el lema de «no dejar a nadie atrás».

Se dice que pretende avanzar hacia sociedades con un crecimiento económico inclusivo y mayor cohesión y justicia social, en paz y con un horizonte medioambiental sostenible, explicando cómo ha de procederse en los 17 objetivos de desarrollo sostenible (ODS), que cubren todas las políticas públicas domésticas, la acción exterior y la cooperación para el desarrollo. Se ha puesto de manifiesto que los ODS son universales, se aplican por igual a países desarrollados y en vías de desarrollo, abordan las raíces de la pobreza, la desigualdad y la degradación del planeta y pretenden ser profundamente transformadores.

Entre ellos cabe destacar ahora la igualdad de género $\left(\mathrm{n}^{\circ} 5\right)$, el trabajo decente (8) y la reducción de las desigualdades (10) como más próximos al ámbito de la RSC, correspondiendo buena parte de los restantes más a la esfera de la SC, porque ambos conceptos, o más bien sus contenidos, se entremezclan en la referida declaración.

De la concreta formulación de tales principios y objetivos ya se atisba, más o menos claramente y al igual que acontece con otros organismos supranacionales e internacionales al abordar la misma cuestión, lo que posteriormente se hace más evidente en todo cuanto tiene que ver con ello en nuestro ordenamiento jurídico interno y en lo que, de antemano, se constituyen como dos principios capitales: por un lado, el del respeto a los derechos humanos citados en la Constitución Española con alusión explícita a la Declaración Universal de Derechos Humanos como norma de referencia hermenéutica (art 10) y, por otro y en distinto ámbito pero no por ello menos importante, el básico y fundamental del propio ordenamiento en general sin el cual éste no se entiende: el ya citado superprincipio de buena fe.

Desde esa plataforma se construye el concepto de la RSC, que se extiende a áreas que, en principio, pudiera parecer que trascienden del mero ámbito empresarial o corporativo, como el medio ambiente, pero que, en realidad, están fuertemente vinculados al mismo, según se verá más adelante, en tanto en cuanto de ellos de- 
pende también, aunque sea a medio o largo plazo, la propia viabilidad del negocio o su proyección de futuro en una sociedad como la nuestra, decididamente influída y condicionada por abundantes factores externos tanto políticos como sociales y económicos como consecuencia del superdesarrollo de la interdependencia y de la urgente necesidad de atender a la propia supervivencia de un mundo exánime, al que hay igualmente que proteger de la extinción.

En definitiva, la RSC constituye desde su origen y en sustancia, una idea humanista en su concepción y en sus argumentos, los cuales, no obstante y paradójicamente, corren el riesgo -que es necesario advertir desde ahora- de convertirse en irrelevantes y, consecuentemente, ineficaces, ante el irresistible avance de la tecnología y las comunicaciones en su aspecto más negativo.

Sobre esta base y desde otras fuentes, como la ORGANIZACIÓN INTERNACIONAL DEL TRABAJO (OIT), esa Responsabilidad Social se define como "la manera en que las empresas toman en consideración las repercusiones que tienen sus actividades sobre la sociedad y en la que arman los principios y valores por los que se rigen, tanto en sus propios métodos y procesos internos como en su relación con los demás actores. La RSE es una iniciativa de carácter voluntario y que solo depende de la empresa, y se refiere a actividades que se considera rebasan el mero cumplimiento de la ley"5.

En ella se destaca, por tanto, y en primer lugar, que dicho organismo se refiere a la inicial idea de la Responsabilidad social empresarial, que más adelante ha dado paso al término de Responsabilidad Social Corporativa e incluso a la Responsabilidad Social Organizativa, en un devenir inclusivo y ampliado del concepto primitivo en cuanto a los sujetos concernidos y hasta a sus objetivos. De otra parte $\mathrm{y}$, expresamente, indica que la idea supone una mera actitud reflexiva y ponderativa ("toman en consideración") y su carácter voluntario (soft law), haciendo alusión expresa a los referidos stakeholders ("los demás actores") y precisando que las actividades que constituyen su objeto son las que "se considera que rebasan el mero cumplimiento de la ley", otorgándole así un valor adicional o complementario a lo que la normativa establece de antemano.

Expone como notas caracterizadoras de ese concepto su antedicha voluntariedad (las empresas adoptan libremente un comportamiento socialmente responsable yendo más allá de las obligaciones que les impone la ley), que forma parte integrante de la gestión de la

$5 \quad N^{\circ} 1$ Help Desk de la OIT, assistance @ ilo.org 
empresa, que es sistemática, no ocasional, que guarda relación con el desarrollo sostenible y que no reemplaza el papel que desempeñan las autoridades públicas, ni a la negociación colectiva, ni a las relaciones de trabajo.

Es oportuno subrayar desde ahora la mención explícita del concepto de "desarrollo sostenible", que constituye el embrión del más amplio de sostenibilidad, al que después se ha añadido la adjetivación de "corporativa", en un progreso similarmente paralelo al de responsabilidad social de esta clase.

En esa página señala también dicha Organización para justificar su cometido en la materia (precisando incluso los momentos claves de su implicación en años concretos) que "la mayoría de las iniciativas en materia de RSE, comprendidos los códigos de conducta, remiten a los principios que dimanan de las normas internacionales del trabajo, que ha elaborado la OIT. Los convenios de la OIT, una vez ratificados por los países, pasan a ser vinculantes para los gobiernos, los cuales deben promulgar leyes para llevarlos a la práctica. Aunque no son vinculantes para las empresas, los principios dimanados de los convenios de la OIT pueden servir de guía para el comportamiento de las empresas. La OIT desempeña una función consistente en ayudar a promover el diálogo entre los gobiernos, las organizaciones de trabajadores y de empleadores y en prestar asistencia y proporcionar instrumentos para entender mejor la dimensión laboral de la RSE".

En 2009 La OIT creó el servicio Help-desk que dice proporcionar a los mandantes y a las empresas acceso fácil a información, asistencia, remisión y asesoramiento en lo relativo a la RSE y la aplicación de las normas del trabajo.

En esa línea, y ya mucho antes (casi cuarenta años atrás), la Declaración EMN de ese organismo (Declaración Tripartita de la OIT sobre las empresas multinacionales y la política social), adoptada por el Consejo de Administración en su 204 reunión (Ginebra, noviembre de 1977) y enmendada en las 279 (noviembre de 2000), 295 (marzo de 2006) y $329^{a}$ (marzo de 2017) constituye una declaración de principios sobre las empresas multinacionales y la política social, donde se trata, entre otros extremos, de prácticas inclusivas, responsables y sostenibles en el lugar de trabajo. Es, señala la Organización, "un instrumento global en esta materia elaborado y adoptado por gobiernos, empleadores y trabajadores de todo el mundo, sus principios están dirigidos a empresas multinacionales y además, a gobiernos y organizaciones de empleadores 
y trabajadores cubriendo las áreas de empleo, formación, condiciones de trabajo y vida y relaciones industriales, así como la política general y están basados en las normas internacionales del trabajo (Convenios y Recomendaciones de la OIT), facilitando, en fin, la divulgación y el entendimiento de la Agenda de Trabajo Decente en el sector privado, un concepto, este último, en evidente relación con el de responsabilidad social en este ámbito", añadiéndose que se ha enmendado en varias ocasiones, la última, en marzo de 2017 incluyendo "nuevas normas del trabajo y resultados en materia de política adoptados por la Conferencia Internacional del Trabajo, los Principios rectores sobre las empresas y los derechos humanos, aprobados por el Consejo de Derechos Humanos en 2011, y la adopción de la Agenda 2030 para el Desarrollo Sostenible.... de manera que se ha "enriquecido la Declaración EMN al fortalecer y añadir principios que abordan cuestiones específicas en materia de trabajo decente relativas a la seguridad social, el trabajo forzoso, la transición de la economía informal a la economía formal, los salarios, la seguridad y la salud, el acceso a mecanismos de reparación y la indemnización de las víctimas. Esto también se ha logrado mediante la descripción a grandes rasgos de las diferentes funciones que desempeñan distintos actores en la consecución del objetivo de la Declaración EMN, acorde a los Principios rectores sobre las empresas y los derechos humanos: puesta en práctica del marco de las Naciones Unidas para "proteger, respetar y remediar".

Asimismo ha expresado en el texto de su $5^{\mathrm{a}}$ edición (17 de marzo de 2017) que "es el único instrumento de la OIT que brinda orientación dirigida directamente a las empresas sobre política social y prácticas inclusivas, responsables y sostenibles en el lugar de trabajo. Es el único instrumento global en esta materia elaborado y adoptado por gobiernos, empleadores y trabajadores de alrededor del mundo. La Declaración sobre las EMN se adoptó allí casi 40 años (modificada en dos ocasiones en 2000 y 2006) y revisado en 2017. Los principios de la Declaración EMN están dirigidos a empresas multinacionales, gobiernos y organizaciones de empleadores y trabajadores y cubren las áreas de empleo, formación, condiciones de trabajo y vida y relaciones industriales, así como la política general. Todos sus principios están basados en las normas internacionales del trabajo (Convenios y Recomendaciones de la OIT). La Declaración EMN facilita la divulgación y el entendimiento de la Agenda de Trabajo Decente en el sector privado". ${ }^{6}$

6 Organización Internacional del Trabajo (OIT) ilo. org 
Por su parte, la ORGANIZACIÓN PARA LA COOPERACIÓN Y EL DESARROLLO (OCDE), que posee su propio Observatorio en la materia, creó en 1976 unas Líneas Directrices (revisadas en 2011) para empresas multinacionales, que son recomendaciones dirigidas a éstas por los gobiernos enunciando principios y normas voluntarias para una conducta empresarial responsable en terrenos como publicación de informaciones, empleo y relaciones laborales, medio ambiente, lucha contra la corrupción, intereses de los consumidores y ciencia y tecnología, habiendo dado ese último año 2011 una Declaración OCDE Watch acerca de la actuación de dichas Líneas, introduciendo, entre otras, disposiciones acerca de los derechos humanos que desarrolla en varios puntos o apartados. Las Directrices actualizadas y la Decisión conexa fueron adoptadas por los 42 gobiernos adherentes el 25 de mayo de 2011 en la Reunión Ministerial conmemorativa del 50 Aniversario de la $\mathrm{OCDE}^{7}$.

Entre los cambios introducidos a las Directrices figuran:

- Un nuevo capítulo sobre derechos humanos, acorde con los Principios Rectores sobre las Empresas y los Derechos Humanos: puesta en Práctica del Marco de las Naciones Unidas para "Proteger, Respetar y Remediar".

- Un enfoque nuevo y amplio en relación con el principio de la debida diligencia y la gestión responsable de la cadena de suministro, que implica un avance significativo en comparación con las anteriores propuestas.

- Cambios sustanciales en numerosos capítulos especializados, tales como Empleo y relaciones laborales; Lucha contra la corrupción, las peticiones de soborno y otras formas de extorsión; Medio ambiente; Intereses de los consumidores; Divulgación de información y Cuestiones tributarias.

- Una guía de procedimiento más clara y más estricta para fortalecer el papel que juegan los PNC (Punto Nacional de Contacto), mejorar su desempeño y fomentar la equivalencia funcional.

- Una agenda proactiva con el fin de ayudar a las empresas en el cumplimiento de sus responsabilidades a medida que surgen nuevos desafíos.

\footnotetext{
7 Líneas Directrices de la OCDE para Empresas Multinacionales, oecd. org
} 
Su precitado PNC, en fin, constituye, en el marco del referido Observatorio, una instancia para la promoción, y divulgación del efectivo cumplimiento de las repetidas Líneas Directrices ${ }^{8}$

EL FONDO MONETARIO INTERNACIONAL (FMI), EL BANCO MUNDIAL (BM), ambos creados en la conferencia internacional de Bretton Woods, en 1944 y cuyas actividades se complementan, la Organización Mundial de la Salud (OMS) y la Organización Mundial del Comercio (OMC), en fin, son, con algunos más, otros tantos organismos comprometidos con la idea y filosofía de la RSC $^{9}$, cabiendo acaso destacar el primero de ellos y debiendo añadirse a la relación de sus respectivos contenidos en la materia la norma de orientación ISO 26000 sobre responsabilidad social ${ }^{10}$ y la certificación SA 8000. ${ }^{11}$

El instrumento del FMI más directamente relacionado con los objetivos de la RSC es el tercer grupo de códigos y normas que dicho organismo y el BM reconocieron como base para elaborar los Informes sobre la Observancia de los Códigos y Normas (IOCN) destinados a aquellos gobiernos que los solicitan voluntariamente, y que hace referencia a la integridad del mercado.

Los Principios de Gobierno Corporativo desarrollados por la OCDE relativos a los derechos de los accionistas y su tratamiento equitativo, la comunicación y la transparencia y las responsabilidades del Consejo de Administración de las empresas, son, todos ellos, conceptos y principios claramente comunes a la RSC, habiéndose dicho que es muy positivo que el FMI y el BM se amparen en ellos y los consideren como el código internacional de referencia para elaborar informes sobre la gestión de empresas, pero puntualizándose, por otro lado, que los informes relacionados con la integridad del mercado los lleva a cabo el BM y que el FMI, por su parte, no posee

8 Observatorio de Responsabilidad Social Corporativa. observatoriorsc.org

9 Véase Abenoza, S.; Ayuso, S.; Soto, J. P., "Implicación de los organismos mundiales en la Responsabilidad Social Corporativa", Marzo 2008. Escola Superior de Comerç Internacional, Cátedra Mango de Responsabilidad Social Corporativa. Universitat Pompeu Fabra.

10 Se ha definido a las normas ISO (International Organization for Standardization) como "documentos que especifican requerimientos que pueden ser empleados en organizaciones para garantizar que los productos y/o servicios ofrecidos por dichas organizaciones cumplen con su objetivo".

11 Norma de la Social Accountability International (SAI) Entre las áreas cubiertas por la SA 8000 están el trabajo infantil, el trabajo forzado, la salud y la seguridad, la libertad de asociación y negociación colectiva, discriminación, prácticas disciplinarias, horas de trabajo, compensaciones y sistemas de gestión. Es una norma certificable que ha tenido varias revisiones. Existe una guía de aplicación que se puede consultar en www.sa-intl.org . 
herramientas ad hoc ni ha desarrollado pauta alguna relativa a los derechos humanos, laborales o el medio ambiente.

\section{Tanto la ORGANIZACIÓN MUNDIAL DE LA SALUD (OMS) COMO LA ORGANIZACIÓN MUNDIAL DE COMERCIO (MC), así como otros organismos internacionales en menor medida, parti- cipan, en fin, igualmente y en sus respectivos ámbitos de actuación, en la difusión e implantación y desarrollo de la RSC.}

De la primera (OMS), creada en 1948 en el seno de la ONU y con antecedente en la Organización de la Salud de la Sociedad de Naciones, cabe destacar que, independientemente de su trayectoria anterior en el ámbito que su nombre proclama, se alineó desde un primer momento y como no podía ser de otro modo, con los Objetivos de Desarrollo del Milenio (8) elaborados por aquélla (la ONU) en septiembre de 2000, que deberían cumplirse antes de 2015, habiendo precisado en su decimoprimero programa de trabajo para 2006-2015 como metas más sobresalientes entre otras varias, la igualdad entre hombres y mujeres y los derechos humanos relacionados con la salud y fortalecer la gobernanza, el liderazgo y la rendición de cuentas.

La OMS se ha planteado, según ha dicho, la necesidad de estrategias nacionales de desarrollo de su programa en tanto en cuanto actualmente y más que nunca por el efecto de la globalización, que posee un amplio abanico de posibilidades positivas que hay que potenciar, "la seguridad en materia de salud pública depende de la seguridad de las instalaciones químicas y nucleares y del uso apropiado de sus productos. Por otra parte, también está resultando muy perniciosa para la salud la intensificación de los cambios en los fenómenos climáticos. Unos cambios que, en gran medida, vienen provocados por el desarrollo económico y la sobreexplotación de los recursos naturales.

La salud es obviamente una cuestión de interés para todos y para llegar a un mejor entendimiento de las medidas que pueden mejorar la salud de las personas habrá que llevar a cabo actuaciones a nivel intersectorial y en sectores independientes del sanitario".

Las tesis que maneja la OMS son las de que "los gobiernos, con su asistencia, deberán colaborar con la industria para aplicar un programa de salud pública establecido de común acuerdo siendo necesario adoptar y mantener medidas intersectoriales para transformar los diferentes factores operativos de la salud, es decir, reducir los generadores de riesgo relacionados con los modos de vida, promover intervenciones para abordar los determinan- 
tes sociales y económicos más amplios de la precariedad sanitaria, y promover entornos físicos más saludables y seguros, una mejor nutrición, así como la inocuidad de los alimentos y la seguridad alimentaria".

Por otra parte, la OMS se propone intensificar su actividad en la sociedad civil y el sector privado, incluidas las empresas internacionales de atención de salud y la industria farmacéutica.

En definitiva, su conclusión es la de que "la economía de mercado responsable asistida de las nuevas tecnologías, lleva al adecuado funcionamiento del mercado y produce un aumento del bienestar social y económico, un crecimiento equitativo, prácticas comerciales leales y seguridad y cooperación entre los países.

La primera herramienta creada con el fin de coordinar esfuerzos entre los distintos agentes a nivel internacional es el Reglamento Sanitario Internacional SI (2005). La aplicación eficaz de dicho Reglamento sirve a los sectores de la salud, el comercio y el turismo, aunque también tiene en cuenta intereses políticos y empresariales".

De otro lado, cabe destacar su cooperación con la OMC en diversos acuerdos y programas de ésta y con la OCDE y con distintas ONGs o la implantación del Año Mundial de la Salud, que se celebra todos los 7 de abril (La 72 ${ }^{\mathrm{a}}$ Asamblea Mundial de la Salud designó 2020 como el Año internacional de los profesionales de enfermería y de partería y en 2021 se celebra el de los trabajadores del sector sanitario, para reconocer su labor durante el enfrentamiento a la COVID-19) en los que se organizan debates con frecuencia relacionados con la actividad empresarial.

En el ámbito de la programación, de los planes y de las intenciones, pues, parece que aunque todo puede mejorarse, se está desarrollando un trabajo idóneo, sea, o no, del todo suficiente. En consecuencia, hay que desplazar la atención hacia otro sector, que aunque íntimamente vinculado con el anterior, es distinto y viene configurado, en buena parte, por la realidad del momento y las necesidades surgidas en él -que ahora son extraordinarias- como sus hipotéticas soluciones, y que pasan por determinar con claridad y exactitud el origen o causa del problema o por llegar a la conclusión sincera de que no es posible descifrarlos, denunciando, en ese caso, el motivo de tal imposibilidad al mundo entero, sin reservas, porque sólo la verdad nos hace libres y, en consecuencia, dueños de nuestras decisiones, que es el primer requisito para solventar los problemas, sin cierres en falso de los mismos. 
Todavía es prematuro evaluar la gestión de la OMS en la singular y extremadamente grave tesitura de la pandemia COVID19 y la influencia que en sus actividades y decisiones haya podido tener alguna posición interesada. Para ello hace falta una cierta perspectiva histórica que le otorgue objetividad. Pero no cabe duda de que según alcanza a intuir desde una perspectiva externa el ciudadano medio interesado en la materia como es la plurinformación mediática cotidiana, esta enorme tragedia, que rebasa cualquier previsión teórica inicial y que está lejos de resolverse a pesar del tiempo ya transcurrido, va posiblemente a obligar a replantearse, más que algunos de los programas u objetivos, la propia realidad de tal gestión, de su diligencia y de su idoneidad y de la investigación llevada a cabo al respecto. Porque no puede existir ninguna duda de futuro acerca de la imposibilidad de que se mediatice en ningún aspecto su tarea, orientada a obtener cada vez mayores cotas de salud y bienestar social mundial a través de instrumentos plenamente válidos y eficaces en su teórica formulación, como la RSC y la SC, que han de someterse después a la correspondiente ponderación internacional tras la labor general del organismo y su actuación en cada contingencia en función de la magnitud de la misma.

Son sus resultados y no las palabras o los informes ni las actitudes u orientaciones políticas en el marco de situaciones concretas ni ningún elemento fáctico de peso, los que deben deparar el oportuno juicio al respecto. Ello ya ha generado en el pasado inmediato desafecciones unilaterales de primer orden, probablemente excesivas y quizás no del todo justificadas en ese momento y felizmente corregidas después, pero que han lastrado la credibilidad de la entidad y fomentan incluso la crítica infraestructural -aún no planteada formalmente por fortuna- $\mathrm{y}$ cuya/s causa/s podría/n estudiarse y corregirse para evitar de antemano tal efecto y la desconfianza que inevitablemente habría de precederle, quizás ya para mucho tiempo, en perjuicio de la entera humanidad, que precisa, sin lugar a dudas, de un organismo como éste.

La ORGANIZACIÓN MUNDIAL DEL COMERCIO (OMC), según ella misma se define, "es la única organización internacional que se ocupa de las normas que rigen el comercio entre los países. Los pilares sobre los que descansa son los Acuerdos de la OMC, que han sido negociados y firmados por la mayoría de los países que participan en el comercio mundial y ratificados por sus respectivos Parlamentos. El objetivo es garantizar que los intercambios comerciales se realicen de la forma más fluida, previsible y libre posible". ${ }^{12}$

12 Organización Mundial del Comercio, wto.org

(c) UNED. Revista de Derecho UNED, núm. 27, 2021 
Aunque su relación con la idea de la RSC parece un tanto tangencial o indirecta y algo más abundante en materia de SC, cabe reconocerle una labor en ambos ámbitos, del primero de los cuales se menciona ahora lo que sigue.

Dicha organización, en efecto, con la Conferencia de las Naciones Unidas sobre Comercio y Desarrollo (UNCTAD), el Banco Mundial (BM) y el Centro de Comercio Internacional (CCI), tiene reconocida hace tiempo la relación implícita existente entre el comercio y el desarrollo, habiendo iniciado la primera en 2001 diversas negociaciones en los que se adoptaron los «Objetivos de Desarrollo para el Milenio», con el fin de dar un salto cualitativo de ayuda comunitaria a ayuda para el desarrollo. Y a través de una intensa campaña de llamamiento a la conciencia social, muchos países de la UE invitan a sus consumidores a adquirir productos (entre otros los de la denominada "moda ética") en cuya elaboración se cumplen muchos aspectos de responsabilidad social, al darse un trato justo a los trabajadores que elaboran estos artículos, de tal manera que los consumidores (stakeholders) están dispuestos, por tal motivo, a pagar un precio mayor por ellos, pues también son compatibles con el medio ambiente ${ }^{13}$.

El Acuerdo sobre Obstáculos Técnicos al Comercio (Acuerdo OTC) elaborado por la OMC ${ }^{14}$, tiene, en concreto, como objetivo que los reglamentos técnicos, las normas y los procedimientos de evaluación de la conformidad no sean discriminatorios ni creen obstáculos innecesarios al comercio. Al mismo tiempo, el Acuerdo reconoce el derecho de los Miembros de la OMC a aplicar medidas para alcanzar objetivos normativos legítimos, tales como la protección de la salud y la seguridad de las personas o la protección del medio ambiente. Recomienda, en fin, firmemente a los Miembros que basen sus medidas en normas internacionales como medio de facilitar el comercio y sus disposiciones sobre transparencia tienen por objeto crear un entorno comercial previsible.

Se pretende conseguir que las normas y los procedimientos de prueba y certificación de cada país no entorpezcan ni sean obstáculos innecesarios para el comercio, sin perjuicio de reconocer el derecho de los países a adoptar las normas que consideren apropiadas tanto para la protección de la salud y la vida de las personas como de los animales o la preservación de los vegetales, para la protección del medio ambiente o en defensa de intereses de los consumido-

13 "La RSE requisito del comercio exterior", comunicarseweb.com 28/03/2011

14 Organización Mundial del Comercio wto.org 
res. El Acuerdo contiene un código de buena conducta por el que se rigen los órganos gubernamentales, no gubernamentales o industriales, para la preparación, adopción y aplicación de normas voluntarias. Los Miembros e incluso los observadores pueden comentar en su Comité la aplicación del Acuerdo con el objetivo de allanar el camino para que las disposiciones sean efectivamente aplicadas y con mayor eficiencia. Estos debates se articulan en torno a cuestiones genéricas, interdisciplinares, como la transparencia, la observancia de normas, la evaluación de la conformidad o las buenas prácticas de reglamentación. A lo largo de los años, el Comité OTC ha adoptado una serie de decisiones y recomendaciones para facilitar la aplicación del Acuerdo OTC.

De otra parte ${ }^{15}$, el Comité de Comercio y Medio Ambiente de dicho organismo, creado en 1994, ha incorporado las cuestiones relativas al medio ambiente y el desarrollo sostenible en la labor de la OMC para estudiar los problemas que surgen cuando las políticas en materia de medio ambiente tienen efectos importantes en el comercio, y las soluciones que adopte tienen que ajustarse a los principios de su sistema de comercio.

En materia de derechos laborales, otra de las dimensiones de la RSC, la situación podría ser mejor. Se ha dicho que muchos países son de la opinión que la OMC habría de jugar un papel clave en la imposición del respeto por las normas laborales como requisito indispensable para el comercio internacional. Con seguridad, éste sería un avance significativo en el ámbito de los derechos laborales. Sin embargo, su papel ha sido delegado en la OIT, y la OMC no se ha pronunciado en la cuestión ni ha creado ningún resorte que se ocupe de este tema.

Aun así, se ha destacado que la OMC "encontró la manera de promover la RSC en un mercado específico, el de diamantes, habiendo sido la primera vez en que la OMC aprobó una renuncia a sus propios acuerdos de libre comercio con el fin de proteger los derechos humanos, y la primera vez en que una organización internacional vinculaba directamente la RSC con un acuerdo comercial. Sin embargo, se trató de una medida temporal, muy lejos de lo que podría ser un vínculo estable entre RSC y comercio".

Asimismo se destaca que "otro caso de protección de los derechos humanos por parte de la OMC fue el del acceso de China a la

15 Para cuanto se ha dicho y sigue en relación con la OMC puede verse la obra ya citada "Documentos de trabajo de la Cátedra MANGO de RSC - ESCI Implicación de los organismos mundiales en la RSC", págs 63 y ss. 
Organización. En el protocolo de acceso, los países miembros impusieron como condición "la administración uniforme de la ley china" a lo largo del país, obligando de esta manera al gobierno a notificar sobre aquellas leyes y medidas relevantes en referencia a las áreas económicas especiales. Esta medida se llevó a cabo para proteger los derechos laborales, porque el gobierno chino había creado zonas donde intentaba estimular las exportaciones y la inversión extranjera mediante la exención fiscal y la libertad de incumplimiento de las normas laborales".

No obstante todo ello, empiezan a soplar aires recientes de reforma de la OMC, algo más que sugeridos desde instituciones de gran calado, como la UE.

En efecto, la Comisión Europea dio el 18 de febrero de 2021 un comunicado de prensa presentando su estrategia comercial para los próximos años donde ya se indica expresamente entre otros extremos que más adelante veremos, que "En respuesta a los retos actuales, la estrategia da prioridad a una importante reforma de la Organización Mundial del Comercio que abarque compromisos mundiales en materia de comercio y clima, nuevas normas sobre el comercio digital, normas reforzadas para hacer frente a las distorsiones de la competencia y el restablecimiento de su sistema de solución de diferencias vinculante"16.

Y en referencia ya a LA UNIÓN EUROPEA (UE), procede precisar que merece mención especial en esta materia, en primer lugar por constituir un conjunto de naciones con una filosofía común y en democracia que se rige por unas mismas normas en amplios aspectos, a la que sus miembros han hecho cesiones de soberanía en diferentes áreas que afectan a cada uno y, en segundo lugar, por estar ello más en consonancia con la superior intensidad de su relevancia jurídica en el tratamiento del concreto tema de la RSC y, en fin, porque ya desde un principio, se planteó dicha cuestión en su momento con un carácter pionero, sugiriendo una serie de prácticas empresariales planificadas e integradas en su gestión estratégica de las organizaciones en su conjunto con el objetivo de lograr el equilibrio del desarrollo en los ámbitos económico, social y mediambiental de los países miembros. Ello se refleja ya, sobre todo, a partir del Consejo Europeo de Lisboa de 2000 que diseña la Estrategia (Agenda o Proceso) de Lisboa, consistente un plan de desarrollo

16 Comunicado de prensa de la Comisión Europea para dar a conocer su objetivo por el que "establece el rumbo para una estrategia comercial de la UE abierta, sostenible y firme”. Comisión Europea, ec. europa.eu 18 febrero 2021 
de la Unión Europea (UE) y fue aprobado por el Consejo Europeo en Lisboa el 23 y 24 de marzo de 2000; el Consejo de Gotemburgo (2001), la Agenda Social de Niza (2001) y fundamental el Libro Verde de la Comisión Europea, también de 2001.

La primera mención a la RSE en el marco europeo tuvo lugar en el Consejo de Lisboa, celebrado en marzo del 2000, que marcó como objetivo estratégico para la siguiente década "convertir Europa en la economía basada en el conocimiento más competitiva

y dinámica del mundo, capaz de crecer de manera sostenible, con más y mejores empleos y con mayor cohesión social", y consideró que ello requería una estrategia global.

En las Conclusiones de la Presidencia del Consejo de Niza de diciembre de 2000 se insiste, basándose en la Comunicación que fue presentada por la Comisión en junio de 2000, entre otros extremos, en que es necesario poner en marcha medidas estratégicas relacionadas con la RSE con el objetivo de lograr un acuerdo sobre un programa social europeo y su posterior desarrollo.

La Resolución sobre el Seguimiento de la Estrategia de Lisboa, de diciembre de 2003, insta a las empresas a comprometerse seriamente con su responsabilidad social, resaltando los objetivos establecidos en esta materia RSE por el Consejo de Lisboa. Con dicho fin propone un método de coordinación así como medidas a tomar en las materias que concreta en relación dichos objetivos.

Con el Libro Verde para fomentar un marco europeo para la responsabilidad social de las empresas se presenta un texto elaborado con el fin de contribuir al desarrollo económico, social y medioambiental en Europa y que promueve un debate en pro de hallar la mejor fórmula de propiciar los objetivos europeos en materia de RSE respetando las iniciativas internacionales al respecto.

Dicho documento vuelve a tratar los rasgos fundamentales del concepto de RSE en Europa, insistiendo en su carácter voluntario, que no significa una exención del cumplimiento de las normas imperativas en materia laboral, social o medioambiental que les pueda ser de aplicación, sosteniendo que la idea "supone ir más allá: se trata de desarrollar una economía basada en el conocimiento, competitiva y dinámica pero, a su vez, social y medioambientalmente comprometida". 
Ya se escrito como conclusión de un interesante estudio en la materia ${ }^{17}$ que "desde el Libro Verde de 2001 hasta hoy, se ha mantenido una misma línea conceptual en el seno de la UE en materia de RSE, con impulsos crecientes en cuanto a su concreción: el reiterado carácter voluntario de la RSE, lo cual supone, que la implantación de prácticas por parte de las empresas vaya más allá de la mera observancia de reglas impuestas. Estas prácticas deben integrarse de pleno en la estrategia empresarial y gestión diaria de los negocios, permitiendo el deseado equilibrio entre los polos económico, social y medioambiental.

La UE se reconoce pionera en su trabajo sobre la RSE, pues se trata de la única instancia de carácter supranacional que lo ha abordado hasta el momento con ese nivel de alcance y concreción, aunque recuerda la necesidad de cohesión y puesta en común de buenas prácticas e iniciativas novedosas, así como la importancia del intercambio de ideas y entre actores empresariales, sociales y politicos, debiendo las Administraciones públicas adoptar una función coordinadora e impulsora de estas iniciativas"

Otros puntos relevantes o highlights de toda la trayectoria de la UE en la materia pueden citarse comenzando con la reseña de que en el año 2002 vio la luz el Foro Multilateral Europeo sobre RSE, hallándose equilibradamente representados en él empresarios y sus organizaciones, sindicatos, asociaciones profesionales, consumidores y sociedad civil, habiendo sido invitadas también, en calidad de observadoras, algunas otras instituciones de la UE.

Con un cierto criterio selectivo en las iniciativas dado su número y extensión, la que, posiblemente, más merece ser destacada a continuación es la Comunicación de la Comisión al Parlamento Europeo, al Consejo y al Comité Económico y Social, de marzo de 2006, bajo el sugerente título "Poner en práctica la asociación para el crecimiento y el empleo: hacer de Europa un polo de excelencia de la RSE".

En ella, la Comisión vuelve a hacer hincapié en el carácter voluntario de la RSE para las empresas y valora el papel activo que los agentes económicos pueden tener en la conciliación de los objetivos económicos, sociales y medioambientales de la UE. Tras constatar que la economía de mercado prevalece en la escena global actual, se señala la necesidad de fijarle límites y favorecer el bienestar social, para lo cual las empresas no solo han de cumplir con los requisitos

17 García-Ochoa Mayor, David; Budova, D.; "Proyectos comunitarios en materia de RSE y concreción en España”, bufete Uría Menéndez, uría.com 
mínimos establecidos en las normas jurídicas, sino que también deberían colaborar eficazmente al desarrollo de la RSE.

El Tratado de Lisboa de 2007, por el que se modifican el Tratado de la Unión Europea y el Tratado constitutivo de la Comunidad Europea -que, entre otros extremos, hace que la Carta de los Derechos Fundamentales de la Unión Europea sea vinculante jurídicamentehabla más explícitamente en su plan de acción 2011-2014 tanto de impulsar la educación en materia de RSE como también las políticas nacionales y regionales en dicho tema, como en las grandes empresas, como, en fin, introducir al respecto relaciones con otras regiones, refiriéndose expresamente a conceptos íntimamente vinculados a la RSE como los códigos de buenas prácticas, la transparencia sobre los aspectos sociales medioambientales y los derechos humanos.

Y dando un salto cualitativo en el tiempo por lo antedicho, la Comunicación de la Comisión COM (2011) 681 final, o Comunicación de la Comisión al Parlamento Europeo, al Consejo, al Comité Económico y Social Europeo y al Comité de las Regiones de estrategia renovada de la UE para 2011-2014 sobre la responsabilidad social de las empresas, establece en su apartado 3.1 un nuevo y más amplio diseño del concepto al señalar que. ${ }^{18}$ "La Comisión presenta una nueva definición de la RSE, a saber, "la responsabilidad de las empresas por su impacto en la sociedad». El respeto de la legislación aplicable y de los convenios colectivos entre los interlocutores sociales es un requisito previo al cumplimiento de dicha responsabilidad. Para asumir plenamente su responsabilidad social, las empresas deben aplicar, en estrecha colaboración con las partes interesadas, un proceso destinado a integrar las preocupaciones sociales, medioambientales y éticas, el respeto de los derechos humanos y las preocupaciones de los consumidores en sus operaciones empresariales y su estrategia básica, a fin de:

- maximizar la creación de valor compartido para sus propietarios/accionistas y para las demás partes interesadas y la sociedad en sentido amplio;

— identificar, prevenir y atenuar sus posibles consecuencias adversas".

$\mathrm{Y}$ añade en su punto 3.3 que"la RSE abarca, como mínimo, los derechos humanos, las prácticas de trabajo y de empleo (como la

18 Puede verse al respecto "La Responsabilidad Social Empresarial en la Unión Europea”, Moreda Retortillo, Olatz, 2014, |olatzmoreda@hotmail.es

(C) UNED. Revista de Derecho UNED, núm. 27, 2021 
formación, la diversidad, la igualdad de género y la salud y el bienestar de los trabajadores), las cuestiones medioambientales (como la biodiversidad, el cambio climático, el uso eficiente de los recursos, la evaluación del ciclo de vida y la prevención de la contaminación) y la lucha contra el fraude y la corrupción. La participación de las comunidades locales y el desarrollo, la integración de las personas con discapacidad y los intereses de los consumidores, incluida la intimidad, forman parte también de la agenda sobre la RSE. Se admite que la promoción de la responsabilidad social y medioambiental en la cadena de suministro y la divulgación de información no financiera son aspectos transversales importantes. La Comisión ha adoptado una Comunicación sobre las politicas de la UE y el voluntariado en la que reconoce el voluntariado, entre los trabajadores como una expresión de la RSE".

Como se ha resumido en los medios de comunicación ${ }^{19}$, "entre las novedades de esta nueva Comunicación, además de la citada definición, se hace especial hincapié en la mejora de la transparencia y el apoyo a las pymes. Un apoyo que se materializará en un programa de facilidades para las mismas.

En este sentido, varios de los nuevos compromisos europeos están enfocados a esta mejora de la transparencia para generar confianza. El primero y más ambicioso es una propuesta legislativa sobre transparencia de la información social y medioambiental que está sometida ahora mismo a revisión, y que ha levantado las suspicacias o preocupaciones de algunos países, como es el caso de Alemania. Ello es bien recibido por expertos comunitarios que vienen reclamando la necesidad de una regulación mínima, viendo en esta propuesta un avance importante en materia de RSE dentro del marco de la voluntariedad. En este sentido, la Comisión aboga también por mejorar los procesos de auto-regulación y co-regulación, entendiendo que son mecanismos eficaces de reglamentación cuando son diseñados de manera apropiada. En este sentido, está previsto iniciar en 2012 un proceso de elaboración de un código de buenas prácticas en esta materia".

Además de estos aspectos, la Comisión propone en esta materia otras medidas para los próximos años:

- mejorar la notoriedad de la RSE y la difusión de las buenas prácticas

- mejorar y medir el grado de confianza que inspiran las empresas, para lo que se abordará la cuestión de las prácticas

19 Diario Responsable 30/12/2011 diario responsable.com 
comerciales engañosas en relación al impacto medioambiental de los productos,

- Por último y a igual nivel de importancia, conseguir que las empresas aprecien la retribución de la RSE, pues como destaca la Comisión, "a pesar de que los efectos de la RSE sobre la competitividad son cada vez más reconocidos, son muchas las compañías que todavía tienen dilemas acerca de que un comportamiento socialmente responsable pueda no ser el más beneficioso financieramente, al menos a corto plazo".

El 16 de febrero de 2021 una noticia publicada en el Observatorio de Responsabilidad Corporativa ${ }^{20}$ señalaba que "a mediados de 2021 se espera una primera propuesta por parte de la Comisión Europea de directiva de debida diligencia empresarial. De momento, el Parlamento Europeo ha aprobado un informe sobre lo que debería contener dicha directiva", añadiendo acto seguido que "el pasado 27 de enero la Comisión de Asuntos Jurídicos del Parlamento Europeo aprobó, casi por unanimidad de todos los grupos políticos (26 votos a favor, 1 en contra y 1 abstención), el informe legislativo sobre la debida diligencia empresarial y la responsabilidad de las empresas.

El informe, aunque no es vinculante, manda un claro mensaje del Parlamento a la Comisión Europea para que presente una propuesta formal de ley de debida diligencia empresarial de la UE, es decir, una ley que exija a las empresas, incluidas las instituciones financieras, que aborden los riesgos e impactos sobre los derechos humanos, el medio ambiente y la gobernanza a lo largo de sus cadenas globales de suministro".

Se ha dicho también en tal texto que la aprobación de este informe representa un paso importante, pues se orienta hacia la "obligación de debida diligencia a algunas empresas, reconoce la necesidad de imponer sanciones por el incumplimiento, incluidas las administrativas, y crea una responsabilidad civil por los daños causados o la falta de debida diligencia.

También, el informe pone el foco en la transparencia, en la presentación de informes y la divulgación de información por parte de las empresas, así como en la importancia de incluir a las partes interesadas -como las comunidades locales o los sindicatos- en el proceso de debida diligencia....

20 febrero 16, 2021, Illescas, A. ; Observatorio de Responsabilidad Social, observatoriorsc.org 
....Constituye un buen punto de partida que la propuesta de la Comisión deberá mejorar y así contar con una propuesta legislativa más ambiciosa que realmente funcione en la práctica y proporcione acceso a la justicia a las víctimas de violaciones de los derechos humanos.

Con esta intención, la ECCJ (European Coalition for Corporative Justice) y otras organizaciones de sociedad civil, detallan aquellos aspectos que habría que mejorar y armonizar con relación a la normativa de debida diligencia.

Paralelamente, la Comisión Europea en octubre de 2020 abrió una consulta pública sobre la iniciativa de Gobierno Corporativo Sostenible, que se espera que introduzca un marco normativo de la UE sobre la diligencia debida de las empresas durante el segundo trimestre de 2021."

Parece oportuno aclarar que la referencia que se hace a la ECC o Coalición Europea por la Justicia Corporativa es a una ONG de la Civil Society que busca fomentar la RSC (Social Accountability o AC) y la justicia. Con 21 grupos miembros que representan a más de 250 organizaciones de 15 países y reúne a las plataformas nacionales de la Civil Society (NGO-CSO's), dicha ECCJ es, según señala en el texto de su webb, la única coalición europea que reúne campañas europeas y plataformas nacionales de ONG, sindicatos, organizaciones de consumidores y académicas para promover la responsabilidad corporativa. Busca abordar algunas de las causas fundamentales de la injusticia empresarial mejorando las leyes europeas que rigen las actividades comerciales y aumentando el acceso a la justicia para las víctimas de abusos contra los derechos humanos y considera que los mecanismos de responsabilidad social corporativa también deben basarse en los marcos y principios jurídicos internacionales que sirven como base de la justicia social. Es miembro del Foro Europeo Multiactores de RSE. ${ }^{21}$

Por otra parte y como se anticipó al exponer cuanto se refiere a la OMC, la Comisión Europea dio el 18 de febrero de 2021 un comunicado de prensa presentando su estrategia comercial para los próximos años en los siguientes términos además de lo ya expresado: "La estrategia, que refleja la idea de autonomía estratégica abierta, parte de la apertura de la UE para contribuir a la recuperación económica mediante el apoyo a las transformaciones ecológica y digital, y hace un hincapié renovado en el refuerzo del mul-

21 https://eulacfoundation.org/es/mapeo/coalición-europea-de-justiciacorporativa 
tilateralismo y en la reforma de las normas comerciales mundiales para velar por que sean justas y sostenibles. Cuando sea necesario, la UE adoptará una postura más firme en la defensa de sus intereses y valores, incluso a través de nuevos instrumentos.

A la hora de hacer frente a uno de los mayores retos de nuestro tiempo y de responder a las expectativas de los ciudadanos europeos, la Comisión sitúa la sostenibilidad en el centro de su nueva estrategia comercial, en apoyo de la transformación fundamental de su economía en una economía climáticamente neutra. La estrategia abarca una serie de grandes medidas centradas en el refuerzo de las normas comerciales mundiales y en la contribución a la recuperación económica de la UE.

Acerca de la nueva estrategia, Valdis Dombrovskis, vicepresidente ejecutivo y comisario de Comercio, ha declarado lo siguiente: «Los retos a los que nos enfrentamos requieren una nueva estrategia de política comercial de la UE. Necesitamos un comercio abierto y basado en normas para contribuir a recuperar el crecimiento y la creación de empleo después de la COVID-19. Asimismo, la política comercial debe sostener plenamente las transformaciones ecológica y digital de nuestra economía y liderar los esfuerzos mundiales por reformar la OMC. También deberá ofrecernos los instrumentos necesarios para defendernos cuando nos enfrentemos a prácticas comerciales desleales. Estamos siguiendo un rumbo abierto, estratégico y firme, haciendo hincapié en la capacidad de la UE para tomar sus propias decisiones y para configurar el mundo en derredor mediante el liderazgo y el diálogo, de manera que refleje nuestros intereses y valores estratégicos».

La nueva estrategia reforzará la capacidad del comercio para apoyar las transiciones digital y climática, en primer lugar al contribuir a la consecución de los objetivos del Pacto Verde Europeo y, en segundo lugar, al eliminar las barreras comerciales injustificadas en la economía digital para aprovechar las ventajas de las tecnologías digitales en el comercio. Al reforzar alianzas como la asociación transatlántica y prestar mayor atención a los países vecinos y a África, la UE será más capaz de configurar el cambio mundial.

Paralelamente, la UE adoptará una actitud más estricta y firme en relación con la aplicación y el cumplimiento de sus acuerdos comerciales, la lucha contra el comercio desleal y el tratamiento de los problemas de sostenibilidad. La UE está intensificando sus esfuerzos por garantizar que sus acuerdos reporten las ventajas negociadas a sus trabajadores, agricultores y ciudadanos. 
Esta estrategia se basa en una consulta pública amplia e inclusiva que ha recibido más de 400 contribuciones de partes interesadas muy diversas y ha contado con actos públicos en casi todos los Estados miembros además de un intenso diálogo con el Parlamento Europeo, los Gobiernos de la UE, las empresas, la sociedad civil y los ciudadanos en general". ${ }^{22}$

Toman ya, pues, carta de naturaleza en el ámbito de la RSC conceptos como diligencia debida y como transparencia, ampliatorios de los límites de dicha responsabilidad pero en todo caso insertos, en sus orígenes y anclaje, en la idea de buena fe inicialmente aludida, conceptos que si bien, como se dice, han estado presentes en todo momento de un modo u otro, ahora resultan más evidentes y que por ello cobran una cierta autonomía dentro del superconcepto, progresándose con ello en la mejor dirección posible en tanto en cuanto se trata de elementos de primer orden en el camino que ha sido marcado de salida y acordes con la responsabilidad misma en la correcta dirección de un mundo más justo y más humano en el sentido espiritual de habitable, esto es, de una sociedad mejor que tan duramente avanza sobre la base de retroceder un tanto y casi constantemente parte del camino que se recorre.

La transparencia supone que no sólo nuestros interlocutores pueden percibir lo que tienen derecho a ver sino que nosotros mismos tenemos ocasión de verificar y contemplar la tarea que realizamos, posibilitando así la corrección de errores apreciados y consiguiendo con todo ello un producto y una prestación mejores y más limpios y erradicando, al menos en buena parte, la falacia, la mentira, los recursos y las mañas que constituyen una suerte de estafa no sólo material sino conductal. Contribuye igualmente a la seguridad en una doble dirección y, por tanto, a la credibilidad y la confianza en lo que se hace y en quien lo hace, sentando las bases de una relación duradera y solvente, en beneficio también, en fin, de nuestro propio entorno, que debiera formar parte de uno mismo.

En cuanto a la diligencia, es la idea opuesta a la pereza y, curiosamente, tiene su origen en un vocablo latino que significa "amar", porque, en efecto, supone acudir con prontitud o realizar del mismo modo la tarea encomendada e incluso la autoimpuesta con el mejor propósito de prestar el más eficaz servicio, lo que evidentemente comporta una carga de cariño indudable tanto a la propia tarea que

22 Comunicado de prensa, ya citado, de la Comisión Europea para dar a conocer su objetivo por el que "establece el rumbo para una estrategia comercial de la UE abierta, sostenible y firme”. Comisión Europea, ec. europa.eu 18 febrero 2021. 
se realiza como a la persona o entidad destinataria cuando a esa diligencia la acompaña la buena ejecución de la labor, sin la cual, por otro lado, no se entiende esa diligencia, que quedaría, en tal caso, reducida a una prontitud sin contenido, lejos de la atención y consideración que en la auténtica diligencia residen.

\section{NEGOCIACIÓN COLECTIVA Y DERECHO NECESARIO}

Se dice que la negociación colectiva y el convenio colectivo como resultado pueden ser mecanismos clave para el desarrollo de la Responsabilidad Social Corporativa (RSC). Sin embargo, "la incorporación de las prácticas de recursos humanos socialmente responsables (SR) que han sido puestas de manifiesto en la literatura como relevantes y que, teniendo en la actualidad cabida y en diversos instrumentos y documentos de las organizaciones (i.e., Planes de Igualdad y Códigos de Conducta, informes anuales, etc.), no han llegado a desarrollarse de una manera exhaustiva en la negociación colectiva, ni plasmado en el convenio colectivo........."

Los resultados indican que hay grupos importantes que "abordan la inclusión y compromiso de las políticas de RSC en su gestión, pero que, sin embargo, no se incorporan de manera explícita en el convenio colectivo". Y se expone como tesis que "su inclusión, de llevarse a cabo...., puede ser un incentivo que permita no sólo atraer, retener y motivar a los mejores empleados, sino una fuente de diferenciación con respecto a otros competidores, dado su carácter vinculante tanto para empresas como para trabajadores". ${ }^{23}$

No cabe olvidar que, como dijo Francesco Carnelutti, los convenios tienen "cuerpo de contrato y alma de ley", de modo que se los puede concebir en esta materia como un modo de introducir la RSC en la obligatoriedad desde la voluntariedad, que es el camino más idóneo a seguir todavía en esta fase.

El art 2 de la Recomendación 91 de la OIT define al Convenio Colectivo como «todo acuerdo escrito relativo a las condiciones de trabajo y de empleo, celebrado entre un empleador, un grupo de empleadores o una o varias organizaciones de empleadores, por una parte, y, por otra, una o varias organizaciones representativas de trabajadores o, en ausencia de tales organizaciones, representantes de

23 "La negociación y el convenio colectivo como herramientas claves para el impulso de la responsabilidad social: análisis en el sector bancario"; Biedma Ferrer, J. M.; López Fernández, M. y

Romero Fernández, P.M.; Management Letters Cuadernos de Gestión ojs.ehu.eus

(C) UNED. Revista de Derecho UNED, núm. 27, 2021 
los trabajadores interesados, debidamente elegidos y autorizados por estos últimos, de acuerdo con la legislación nacional» .

Por su parte, la Constitución Española establece entre los derechos y deberes de los ciudadanos (Sección $2^{\mathrm{a}}$ de su Capítulo II de su Título Primero relativo a los derechos y deberes fundamentales y, en concreto, en su artículo 37.1 que la ley garantiza "el derecho a la negociación colectiva", así como la "fuerza vinculante de los convenios", lo que se recoge en el art 4.1.c) del ET y se desarrolla en su Título III (arts 82-92), de manera que es un derecho de alto rango que hace que el pacto que resulte de su ejercicio entre los agentes sociales (el propio convenio colectivo) tenga esa especial consecuencia, haciendo de él, como fuente de la relación laboral reconocida en el artículo 3.1.b), una norma para dichas partes, de mayor o menor extensión según el ámbito que abarque.

Tiene, pues, dicho pacto un alcance tanto social como económico determinante en tanto no se oponga a la ley misma (art 85.1 ET) y por esa vía y en dicho ámbito se introducirán cuantas previsiones -de obligado cumplimiento entre los concernidos- afecten a cuestiones tales como la igualdad de mujeres y hombres, salud laboral, medio ambiente, derecho de información, etc, etc, etc.

Como dice el artículo 82. 1 y 2 de la norma estatutaria, "los convenios colectivos, como resultado de la negociación desarrollada por los representantes de los trabajadores y de los empresarios, constituyen la expresión del acuerdo libremente adoptado por ellos en virtud de su autonomía colectiva.

Mediante los convenios colectivos, y en su ámbito correspondiente, los trabajadores y empresarios regulan las condiciones de trabajo y de productividad. Igualmente podrán regular la paz laboral a través de las obligaciones que se pacten"

Así pues, fruto de ese acuerdo libremente pactado, se regulan las condiciones de trabajo y productividad, mejorando, evidentemente, las condiciones legales o supliendo sus lagunas u omisiones, de manera que puede tener (y, de hecho, tiene) perfectamente encaje en ese instrumento negocial cuanto se pueda acordar en materia de responsabilidad y de sostenibilidad dentro de su ámbito, concepto de moderna integración en dicha negociación aunque con resultados en sus contenidos y en su ejecución aún no del todo completos, siendo la idea en este aspecto que, desde la cultura del pacto (que, ante todo, significa respeto, que es un principio de responsabilidad social) y del compromiso resultante, se difundan o propaguen algunos de esos contenidos que puedan recibir finalmente el refrendo de 
la convicción popular acerca de su necesidad o conveniencia y, por esa vía, acceder a un lugar en la normativa general, esto es, al derecho necesario.

En el ámbito de este último ${ }^{24}$, cabe referirse al Real Decreto 221/2008, de 15 de febrero, por el que se crea y regula el Centro Estatal de Responsabilidad Social de la Empresa (CERSE) como órgano dependiente del Ministerio de Trabajo e Inmigración, con carácter asesor y consultivo en materia de RSE, configurándolo como marco de referencia para el desarrollo de la RSE en España, y encargándole el impulso y fomento de las políticas de RSE en nuestro país. Presidido por el Ministro de Trabajo e Inmigración, es un órgano formado por 56 vocales que representan a la Administración, a las organizaciones sindicales y empresariales y a otras instituciones de prestigio en materia de RSE, que funciona como órgano asesor y consultivo del Gobierno para la identificación y promoción de mejores prácticas y propuesta de políticas de RSE al Gobierno.

La creación del CERSE ha significado atender al llamamiento del Consejo de Lisboa de marzo del 2000 en favor de una mayor sensibilidad social de las empresas en el ámbito europeo, concretado posteriormente en el Libro Verde de junio de 2001.

El CERSE funciona a través de distintos grupos de trabajo sobre diferentes materias, y así, transparencia (en el proceso de implantación de prácticas de RSE, transparencia es igual a credibilidad), comunicación y estándares de los informes y memorias de sostenibilidad; consumo e inversión socialmente responsable; la RSE y la educación: sensibilizar, informar, divulgar y formar en materia de RSE a todos los ciudadanos; gestión de la diversidad, cohesión social y cooperación al desarrollo: se trata de incorporar cláusulas sociales en las contrataciones públicas, integrar a colectivos en riesgo de exclusión para su incorporación al mercado de trabajo, y otros temas relativos a la igualdad, los derechos humanos y la diversidad.

Además de la creación del CERSE, cabría destacar en orden cronológico:

— Libro Blanco de la RSE aprobado en junio de 2006 por unanimidad de todos los grupos políticos del Congreso de los Diputados, que es el primer documento de este tipo aprobado en Europa por un parlamento nacional.

24 Sobre cuanto sigue en este punto, vid. García-Ochoa Mayor D. y Budova, "Proyectos comunitarios en materia de RSE y concreción en España", D. pags 1723; Uría Menéndez, uría.com, obra ya citada. 
El documento recomienda que la política pública de desarrollo de la RSE se componga de normas que fomenten iniciativas voluntarias de prácticas empresariales responsables y acuerdos y medidas legislativas que contribuyan a favorecer las conductas responsables de los actores económicos.

- Orden TIN/3440/2009, de 16 de diciembre, del Ministerio de Trabajo e Inmigración por la que se establecen las bases reguladoras de la concesión de subvenciones a las actividades de promoción de la economía social, de la RSE y del trabajo autónomo

- Orden ITC/404/2010, de 22 de febrero del Ministerio de Industria, Turismo y Comercio por la que se establecen las bases reguladoras para la concesión de ayudas públicas a la implantación y desarrollo de la responsabilidad social en las pequeñas y medianas empresas: iniciativa "RSE-PYME". Esta norma se complementó con la Orden ITC/473/2011, de 23 de febrero, por la que se aprueba el Plan Anual Integrado de ayudas para el año 2011 y se establecen medidas para su tramitación y la Resolución de 16 de marzo de 2011, de la Secretaría General de Industria, que convocó para el año 2011 ayudas a la implantación y desarrollo de la RSE en las pymes.

- La Ley 2/2011, de 4 de marzo, de de Economía Sostenible, ya citada, a la que se hará referencia más concreta al examinar de ese modo cuanto se trata acerca de la idea y concepto de sostenibilidad más adelante.

- La Ley 11/2018, de 28 de diciembre, por la que se modifica el Código de Comercio, el texto refundido de la Ley de Sociedades de Capital aprobado por Real Decreto legislativo 1/2010, de 2 de julio y la Ley 22/2015, de 20 de julio, de Auditoría de Cuentas, en materia de información no financiera y diversidad (más escuetamente, Ley de Información No Financiera y Diversidad), exige a determinadas empresas publicar, como parte del reporting anual, información relativa a su gestión social, medioambiental, de derechos humanos y la lucha contra la corrupción y el soborno, tratando de continuar impulsando la Responsabilidad Social Corporativa (RSC) en las empresas. ${ }^{25}$

25 Vid "La nueva Ley que impulsa la Responsabilidad Social Corporativa", 12/03/2019; interempresas.net 
- A la normativa estatal cabe añadir la autonómica de algunas Comunidades como, por ejemplo, la Ley de RSE de Extremadura (Ley 15/2010, de 9 de diciembre).

En otro orden de cosas, en el año 2004 se creó el Observatorio de Responsabilidad Social Corporativa como red de cooperación e investigación y como plataforma de pensamiento en la que se aúnan las iniciativas de distintas organizaciones con el fin último de potenciar la RSE en la sociedad con una serie de líneas estratégicas de actuación tanto para formación y sensibilización en la materia como evaluación y seguimiento del cumplimiento de la normativa en materia de RSE en diferentes ámbitos empresariales; generación de red social, mediante encuentros nacionales e internacionales y colaboración con las Administraciones Públicas para la inclusión de la RSC en la agenda política nacional e internacional.

Todo cuanto precede y otros ejemplos dan medida de la vida que posee la RSC tanto en el ámbito internacional como en el interno y su constante evolución en sentido de desarrollar o reajustar su contenido primigenio, de tal modo que a un comienzo más o menos vacilante o tímido le ha seguido una cada vez mayor reafirmación que lejos de constituir un momento puntual, posee constantes etapas en tal sentido, en buena parte surgidas de la necesidad, a que se ha aludido ya, tanto del ser humano de perfeccionarse como persona y como factor operativo, como de conservar "un mundo que agoniza" en la expresión no por literaria menos acertada ${ }^{26}$, que da medida de

26 Delibes Setién, M. "Un mundo que agoniza”, Edit Plaza Janés. El que probablemente ha sido el más grande escritor español de siglo XX, adelantaba ya en 1973 su percepción del presente-futuro, habiéndose escrito en la presentación y resumen del libro que "condensa su pensamiento, e incluye partes de su discurso de ingreso en la Real Academia Española. Se dice pesimista al escribir sobre una civilización que morirá por su propia avaricia....

Un ensayo para reflexionar sobre nuestro compromiso con el medio ambiente, elaborado con grandes dosis de filosofía, sociología, ecología... "Ética y estética se han dado la mano en todos los aspectos de mi vida", confiesa Delibes. Un hombre comprometido con la conservación del medio ambiente como vía para alcanzar el verdadero progreso.

El autor habla de la sed insaciable de poder del hombre, su afán de dominación y su complejo de superioridad como mal endémicos de las sociedad modernas. Vierte aquí su crítica feroz sobre la falta de humanismo que nos caracteriza. Se aproxima a las consecuencias del éxodo rural y al sometimiento de las mentes para que dejen de funcionar, de pensar, y puedan ser conducidas en aras de un interés oculto mediante la eliminación de la crítica y la publicidad subliminal hasta producirse la propia alienación del ser humano. La despersonalización del hombre que deriva en la creación de auténticas masas amorfas controladas por el poder concentrado en unas pocas manos.

Delibes cree que los mundos de pesadilla de Huxley y Orwell han llegado. Una inteligente teoría acompañada de datos, informes, textos y documentos que la 
un estado de cosas que no hace sino agravarse en todos los espacios y viene exigiendo soluciones inmediatas más que rápidas. Y ahí la convergencia del concepto RSC con el más moderno de SC.

\section{SOSTENIBILIDAD}

Con la genérica expresión de "SOSTENIBILIDAD", sin adjetivar, se ha venido comúnmente haciendo, en principio, referencia a distintas clases de un mismo concepto:

- Sostenibilidad ambiental, con la que se define la que busca preservar la biodiversidad del planeta teniendo en cuenta los otros 2 tipos de sostenibilidad.

- Sostenibilidad económica o conciliación entre desarrollo económico, ambiental y social en una economía competitiva y productiva que beneficie la igualdad, la cohesión social y el empleo de calidad. Garantiza el uso racional de recursos naturales y el respeto hacia el medio ambiente satisfaciendo las necesidades actuales sin comprometer las futuras. Pretende incrementar el bienestar social con un consumo responsable.

- Sostenibilidad social, que ha sido definida en el ya mencionado Diccionario del Español Jurídico diciendo, con remisión expresa al artículo 4 de la Ley de la Comunidad Autónoma de Aragón 11/2014, de 4 de diciembre, que se trata de una "sostenibilidad que busca fomentar las relaciones entre los individuos y el uso colectivo de lo común conjugando crecimiento económico y respeto ambiental con bienestar social, fomentando el mantenimiento y la creación de empleo, protegiendo la seguridad y la salud de las personas, asegurando la reducción de la pobreza y las desigualdades, y evitando las situaciones de exclusión social".

Se trasciende con esta última clase, por tanto, el ámbito de las anteriores integrándolas en esta última.

convierten en hecho constatado y demostrado. Cita varios estudios de la Unesco, la Conferencia de Estocolmo de 1972, el Congreso de París en el 68 y el de Londres del 70. También a Kant, a Mary McCarthy, a Robert Heilbroner, a Miguel Bosquet, a González Ruano... Y reúne a los personajes de sus novelas para explicar por qué son cómo son, seres comprometidos y reflexivos que conviven con su entorno natural". https://elbailedelaspalabras.wordpress.com/2017/06/08/un-mundo-queagoniza-miguel-delibesplazajanes/ 
Más modernamente se ha introducido también en ella la idea de sostenibilidad corporativa, de la que, como su nombre viene a sugerir, no cabe duda que es una especialidad propia del mundo empresarial.

La sostenibilidad corporativa podría entenderse, según algún estudio especializado ${ }^{27}$, como "una evolución natural y necesaria de la responsabilidad social corporativa con el objetivo de vincularla más al valor y al core business de cada empresa. (Hay que) plantear la necesidad de evolucionar el concepto de Responsabilidad Social Corporativa (RSC) hacia la idea de Sostenibilidad Corporativa.........(porque), "la filantropía empresarial le ha ganado la batalla a la RSC (que) hoy se relaciona más con programas sociales no necesariamente vinculados a la actividad de la empresa que con, por ejemplo, la gestión íntegra y ética de las multinacionales en el proceso de globalización, la identificación de nuevas oportunidades de mercado con impacto positivo en la sociedad o la gestión de riesgos derivados del negocio en aspectos sociales, económicos o ambientales. En estos años, en torno a la RSC se ha generado un "efecto halo" asociado a los programas sociales y a la filantropía empresarial, efecto que ha "secuestrado" su verdadera naturaleza...... (de tal manera que) hoy, doce años después de lanzarse el Pacto Mundial, los medios de comunicación, las empresas y la opinión pública perciben que la RSC está vinculada básicamente a la filantropía como palanca de construcción y mejora de imagen, y existen serias dudas de que este concepto pueda abandonar ese efecto halo e incorporarse como una palanca de creación de valor en el core business de las empresas. Por eso, y con el fin de crear valor y aproximarse al negocio, es necesario cambiar".

En definitiva que, según esta opinión, se ha producido un cierto y sustancial desviacionismo que es necesario corregir para no desnaturalizar el concepto primigenio de RSC, que no constituye altruismo o bondad de corazón, según se anticipó, sino conciencia y respuesta ("responsabilidad") al auténtico papel que toca asumir a la empresa y su titularidad para que la relación laboral y lo que de ella trasciende al exterior sea acorde con los principios naturales más ortodoxos, lo que dignifica a la economía de mercado y evita sumirla en un exclusivo contenido económico sin mayor razón que el beneficio, que aunque en la base de esa clase de economía y exigencia primordial de la misma, es consecuencia de la titularidad de los bienes de producción que le es inherente y precedente, la cual ha de cum-

27 "De la RSC a la sostenibilidad corporativa: una evolución necesaria para la creación de valor"; Andreu Pinillos, A.; Fernández Fernández , J-L. researchgate.net

(C) UNED. Revista de Derecho UNED, núm. 27, 2021 
plir una función social como la propiedad de cualquier otra clase, más, si cabe, en un mundo globalizado.

Muy posiblemente haya de convenirse en el acierto de lo expresado en lo que se viene de transcribir pero en cualquier caso, y comenzando por el principio, procede señalar primero que el origen del concepto genérico de "sostenibilidad" como "desarrollo sostenible" (sostenibilidad económica y ambiental conjuntamente), es realmente reciente con el significado con que ahora lo conocemos, al haberse formulado por primera vez (1987) en el seno de la Comisión Mundial sobre Medioambiente y Desarrollo (CMMD) de la ONU apareciendo en el famoso Informe Brundtland de la Dra Gro Harlem Brundtland, titulado "Nuestro futuro común" y elaborado con objeto de comenzar a dar respuestas al impacto de las actividades humanas en el medio ambiente, con lo que, en buena manera, se está identificando el género con la especie de sostenibilidad ambiental.

Se ha expresado gráficamente que "en la actualidad, está cada vez más asumido por gran parte de la sociedad que ese "desarrollo sostenible" es la única salida viable de que dispone la humanidad para satisfacer las necesidades del presente sin comprometer las de las generaciones futuras. La sostenibilidad ha adquirido rango de derecho. Por lo tanto, asumir el desarrollo sostenible supone un compromiso de todo el conjunto de la sociedad, de todos sus componentes y todas sus organizaciones. La Responsabilidad Social Corporativa (RSC) nace cuando las organizaciones son las implicadas en este compromiso, ya sean públicas, privadas, del ámbito académico o social.

Esta nueva forma de pensar y de hacer, en definitiva este nuevo modelo cultural de observar el mundo, conlleva un nuevo modelo socioeconómico, e implícitamente de empresas y empresarios en consonancia, para conseguir una evolución equilibrada entre el desarrollo económico, el desarrollo social y el medio ambiente" 28

También se ha dicho acerca de esta idea ${ }^{29}$ que "si se mezclan el desarrollo sostenible, la responsabilidad social corporativa, la teoría de los grupos de interés y la rendición de cuentas, se obtienen los cuatro pilares de la sostenibilidad corporativa..... Durante estos últimos años, ha habido una importante discusión entre los medios de economía, académicos y opinión pública sobre la sostenibilidad corporativa. A menudo, se utiliza este término junto a otros como "de-

28 "Guía de la Responsabilidad Corporativa para las PYMES"; observatoriorsc.org

${ }^{29}$ Cárdenas Lorenzo, L., "Sostenibilidad corporativa, ¿qué es y de dónde viene?”, Communication / Development / Corporate Sustainability, lauracardenas.es 
sarrollo sostenible" y "responsabilidad social corporativa", e incluso a veces como sinónimo de estos........Pero... puede ser visto como un nuevo, y más evolucionado, paradigma de la gestión empresarial. El término paradigma se usa, deliberadamente, para decir que la sostenibilidad corporativa es una alternativa al modelo tradicional empresarial de crecimiento y maximización de los beneficios. La sostenibilidad corporativa no solo reconoce la importancia del crecimiento y los beneficios empresariales, sino que también requiere que la organización persiga objetivos sociales, especialmente aquellos relacionados con el desarrollo sostenible, como son la protección del medioambiente, justicia y equidad social, así como el desarrollo económico. A través de la revisión bibliográfica, se sugiere que este concepto ha pedido prestados elementos de cuatro conceptos algo más asentados: desarrollo sostenible; responsabilidad social corporativa; la teoría de los grupos de interés, o stakeholders y la teoría de rendición de cuentas", suponiendo esta última, en fin, la responsabilidad de reconocer las acciones por las que la empresa es responsable, con el deber de explicarlas, justificarlas o, cuanto menos, comunicarlas.

Se insertan o se estudia para incorporarlos al sistema y a sus normas avances técnicos, programas, ideas e incluso necesidades constatadas, como digitalización, generalización del uso de energías limpias, comercio justo y teletrabajo, entre otras de diverso signo $\mathrm{y}$ alcance pero concurrentes en el desarrollo sostenible (desarrollo económico + protección medioambiental + justicia social) y finalmente en la propia sostenibidad corporativa como ampliación de la RSC, tanto en su propio contenido como en su tratamiento jurídico, progresándose en buena parte de esos conceptos hacia su total y definitivamente obligatoria implantación en beneficio no sólo del medio ambiente sino de los propios seres humanos, simplemente en cuanto tales, como trabajadores y en cuanto consumidores, potenciando sus derechos o un mejor tratamiento de los mismos.

Y como igualmente se ha escrito en el precitado trabajo "este amplio concepto (desarrollo sostenible) combina economía, justicia social y ciencias medioambientales con la gestión de los negocios, políticas y leyes". Porque, según explicaba la mencionada CMMD en su igualmente referido informe, "no se puede alcanzar el desarrollo sostenible si simplemente se deja en manos de los reguladores gubernamentales y actores políticos. El libro reconoce que la industria tiene un papel muy importante. Los autores argumentaron que, mientras que las organizaciones siempre han sido el motor del desarrollo económico, también necesitan ser más proactivas para equilibrar ese 
papel con la equidad social y la protección del medioambiente, en parte por haber sido la causa de ciertas situaciones no demasiado sostenibles pero también porque tienen acceso a los recursos necesarios para superar estos problemas.

La respuesta, por parte de la industria, a la llamada de atención de la CMMD llegó por etapas, ya que todo el mundo tuvo que lidiar con cómo se suponía que el desarrollo sostenible debería parecer. La primera señal de apoyo llegó de la mano de la Cámara Internacional de Comercio, cuando emitió la Carta de Empresas a favor del Desarrollo Sostenible en $1990^{30}$. Más tarde, en 1992, le siguió el libro Cambio de Rumbo, de Stephen Schimidheiny junto al Consejo de Empresas a favor del Desarrollo Sostenible, (actualmente el Consejo Mundial de Empresas a favor del Desarrollo Sostenible). Ambas publicaciones se centraron en el papel de las organizaciones en el desarrollo sostenible, los autores argumentaron que apoyar al desarrollo sostenible era tanto una necesidad económica como una necesidad medioambiental y social. Desde entonces, numerosos líderes de empresas y organizaciones se han sumado al apoyo de los principios del desarrollo sostenible.

La contribución del desarrollo sostenible a la sostenibilidad corporativa es doble. Por un lado, ayuda a asentar las áreas en las que las compañías se deberían enfocar: la medioambiental, la social y la actividad económica. Por otra parte, pone en común un objetivo social por el que trabajar entre las empresas, los gobiernos y la sociedad civil: la sostenibilidad ecológica, social y económica. Sin embargo, el desarrollo sostenible no es capaz de proveer los argumentos necesarios, por sí solo, para que las empresas tomen conciencia plena de estos problemas. Estos argumentos vienen junto con la responsabilidad social y la teoría de los grupos de interés (stakeholders)....

30 La primera edición de la Carta de ICC para el desarrollo sostenible de las empresas fue adoptada por el Comité Ejecutivo de la Cámara de Comercio Internacional (ICC por sus siglas en inglés) en 1990 y publicada por primera vez en 1991; en el año 2000 la revisó el Grupo de Trabajo para el Desarrollo Sostenible; fue actualizada y ampliada bajo la guía del Grupo de Trabajo sobre Economía Verde y los auspicios de la Comisión sobre Medio Ambiente y Energía en 2014 y lanzada en 2015. En ella se declara que "el término "sostenibilidad/ desarrollo sostenible" puede considerarse como un término global que incluye otros términos tales como "Responsabilidad Social Corporativa (CSR — por sus siglas en inglés)", "Ambiental, Social, de Gobierno (ESG - por sus siglas en inglés)" o línea de "conclusión triple", conforme a lo cual la RSC formaría parte o estaría inserta en la idea de sostenibilidad. International Chamber of Commerce. The World Business Organization. iccmex.mx 
...Esto es, en fin, según se ha escrito en esta materia, lo que la sostenibilidad corporativa toma de los conceptos ya enumerados: el desarrollo sostenible asienta las áreas de acción en las que las empresas se deben centrar, y también promueve la visión de los objetivos sociales por los que las empresas deben luchar. La RSC aporta los argumentos éticos, y la teoría de los grupos de interés aporta argumentos empresariales por los que las empresas deben trabajar hacia los objetivos del desarrollo sostenible. La rendición de cuentas proporciona motivos racionales por los que las empresas deben informar públicamente sobre su actividad en esas áreas".

De todo ello se infiere que, en cualquier caso, Sostenibilidad y RSC son conceptos, cuanto menos, íntimamente relacionados entre sí, y ambos, a su vez, con otros como el de desarrollo económico y social pero resulta preciso puntualizar que la RSC nace en el plano ético previamente señalado y trasladado a la empresa como modelo a seguir voluntariamente de comportamiento en beneficio de todas las partes relacionadas con el proceso productivo e incluso más allá, y que después, a medida que se ha ido tomando conciencia de la necesidad de adoptar criterios de salvaguarda del desarrollo económico implícito en la actividad empresarial y, sobre todo y por encima de todo, del medio ambiente como factor continente de la propia vida en sus diferentes manifestaciones, es cuando se ha intensificado la aplicación de la RSC en la sostenibidad del proceso productivo, del negocio en su conjunto y de la propia sociedad.

Pero ello no debe hacer olvidar que la sostenibilidad es una necesidad de naturaleza más material que la RSC, que ostenta ese rango moral tantas veces repetido, y que, por ello, la sostenibilidad adjetivada de social puede hacer confluir una y otra (rsc y sostenibilidad) a modo de evolución necesaria de ambas ideas hacia un futuro común que urge consolidar, si se quiere que haya un futuro, en cuyo caso, no sólo se habrá ganado la perentoria batalla de la supervivencia sino que se habrá mejorado la calidad del ser humano en su destino ${ }^{31}$.

En cualquier caso, ya hay voces que proclaman que la RSC ha muerto y la sucede la sostenibilidad ${ }^{32}$, citando al respecto la reforma del Código de Buen Gobierno de Sociedades Cotizadas de la Comi-

31 "Al tiempo que apuntamos la importancia instrumental de mantener y expandir las bases materiales de la vida humana, no debemos perder de vista la importancia central de la calidad de la vida humana como un fin en sí mismo", Amartya Sen, "Desarrollo humano y sostenibilidad económica" (2000)

32 Andreu Pinillo, A., "La RSC ha muerto ¡Viva la sostenibilidad!"; diarioresponsable.com 29/06/20 (consulta 08/02/21 19h 58') 
sión Nacional del Mercado de Valores (CNMV) que "abandona el concepto de Responsabilidad Social Corporativa y lo sustituye por el de Sostenibilidad, por ser más amplio y utilizado actualmente, al referirse a aspectos medioambientales, sociales y de gobierno corporativo (ESG)" aludiendo a que el 26 de junio de 2020, la CNMV aprobaba la revisión parcial del Código de Buen Gobierno de Sociedades Cotizadas de 2015, y señalando que la nota de prensa del organismo regulador indicaba que "se realizan algunos ajustes técnicos y se sustituye el término responsabilidad social corporativa por el más amplio y utilizado actualmente de sostenibilidad en relación con aspectos medioambientales, sociales y de gobierno corporativo (ESG)". con cita de las modificaciones introducidas en las recomendaciones 53, 54 y 55 relacionadas con la Responsabilidad Social Corporativa, significando el autor del artículo que ya en 2011 en unión de otro docente ya había escrito un artículo en tal sentido ${ }^{33}$ anticipándose al referido cambio. Y concluye:"Hoy creo que hay que felicitarse por el paso que ha dado el regulador, quien además de pasar conceptualmente de la RSC a la Sostenibilidad, ha modificado el Código en cuatro ejes: (1) fomentar la presencia de mujeres en los consejos de administración; (2) dar mayor relevancia de la información no financiera y la sostenibilidad; (3) prestar más atención a los riesgos reputacionales y en general no financieros; y (4) clarificar los aspectos relativos a la remuneración de consejeros. Definitivamente el regulador se sitúa en el mismo plano que la academia y que algunas empresas punteras. Ahora hace falta que el resto de las compañías terminen por entender de una vez que la RSC nunca tuvo que ver con cuánto de donaba, sino con cómo se ingresaba".

Resulta una posición interesante desde una perspectiva económica que, sin embargo, en el plano estrictamente jurídico y significadamente desde el conjunto pluricomprensivo de la materia puede ser objeto de alguna reserva, de ahí lo que finalmente se obtiene en estas páginas como conclusión, siendo, por otra parte oportuno señalar que en la introducción a la reforma del mencionado Código se indica que "....Finalmente, debe destacarse la incorporación de recomendaciones específicas en materia de responsabilidad social corporativa. El informe de 19 de mayo de 2006 del Grupo especial de trabajo sobre buen gobierno corporativo de las sociedades cotizadas excluyó expresamente de su ámbito los aspectos relativos a la responsabilidad social corporativa.

33 Andreu Pinillo, A. y Fernández Fernández, J.L. "De la RSC a la Sostenibilidad: La evolución necesaria para crear valor", Harvard Deusto Business Review, trabajo ya citado 
Sin embargo, la importancia de la responsabilidad social corporativa de las empresas es una realidad cada vez más asentada, tanto en España como en los países de nuestro entorno, que exige una adecuada atención por parte de los sistemas de gobierno corporativo de las sociedades y, por lo tanto, que no puede quedar al margen de un código de recomendaciones de buen gobierno corporativo.

El proceso de revisión de 2020 afectó, con diferente nivel de intensidad, a las recomendaciones $2,4,6,7,8,14,15,22,24,37,39$, $41,42,45,53,54,55,59,62$ y $64 "$

Considerados la extensión de las citadas recomendaciones y el carácter del Código en cuestión, resulta oportuno no hacer más que remisión a las referidas 53, 54 y 55 en lo que pueda interesar al lector.

Dando por reproducido cuanto se ha venido exponiendo de la labor de organismo internacionales y supranacionales en este ámbito, merece, no obstante destacar acerca de esta sostenibilidad corporativa, a modo también de momentos relevantes que:

- El ya mencionado Consejo de Gotemburgo de junio de 2001, partiendo de las iniciativas contenidas en la Comunicación de la Comisión al Consejo titulada Desarrollo sostenible en Europa para un mundo mejor: estrategia de la Unión Europea para un desarrollo sostenible, sienta las bases por vez primera de una estrategia para ese desarrollo (que define como "la atención de las necesidades de la generación actual sin poner en peligro las de las futuras generaciones") e identifica cinco objetivos medioambientales de carácter prioritario: la lucha contra el cambio climático; la garantía de un transporte sostenible; la respuesta a las preocupaciones de los ciudadanos relativas a las amenazas a la salud pública; una gestión más responsable de los recursos naturales y la integración del medio ambiente en las políticas comunitarias.

De manera, pues, que son metas del desarrollo en cuestión circunscritas a ese medio, uno de los polos de la sostenibilidad pero no el único.

— En el Dictamen del Comité Económico y Social Europeo "La Economía del Bien Común: un modelo económico sostenible orientado a la cohesión social" ECO/378 Bruselas, de 17 septiembre 2015, dicho Comité considera que el modelo de la Economía del Bien Común (EBC) está concebido para incluirse en el marco jurídico europeo y nacional con el fin de avanzar hacia un mercado único europeo a través 
de una economía más ética basada en los valores europeos y los logros de las políticas de responsabilidad social y que la EBC es un enfoque holístico cuyos conceptos están cerca de los valores fundamentales de la Economía Social, la Economía Circular, la Economía Participativa, la Economía de la Funcionalidad, la Economía Basada en los Recursos y la Economía Azul.

En este Dictamen, el Comité Económico y Social Europeo (CESE) propone la transición hacia un mercado europeo ético a través de varias estrategias: crear indicadores del bienestar y el desarrollo social como el Producto del Bien Común y el Balance del Bien Común; elaborar políticas que recompensen a las empresas que contribuyen en mayor medida al bien común, en términos de contratación pública, acceso a los mercados exteriores o ventajas fiscales; fomentar el consumo ético; promover redes de bancos éticos y mercado de valores, etc.

Sobre la base, pues, de la sostenibilidad como idea directriz o modelo del sistema económico a seguir, se maneja repetidamente el principio ético, de clara impronta responsabilista, y que, por ello, va más allá de la defensa del desarrollo económico e incluso de la del Estado de Bienestar en su concepción más material para dotarla de una visión más comprometida con los valores que son la esencia del ser humano ${ }^{34}$.

- En las Conclusiones del Consejo de la Unión Europea sobre la promoción de la economía social como motor clave del desarrollo económico y social en Europa, SOC 711/EMPL 464, Bruselas, de 7 de diciembre de 2015, dicho organismo describe las empresas de economía social e incluye bajo dicho concepto formas organizativas como las cooperativas, mutuas, fundaciones y asociaciones, "así como nuevas formas de empresas sociales", entendiendo por empresa social el concepto definido en el Reglamento sobre el Empleo y la Innovación Social (DO L 347/238 de 20.12.2013)

En dicho Reglamento se señala que la economía y el emprendimiento sociales constituyen una parte integrante de la economía social de mercado pluralista europea y contribuyen de forma importante a lograr una mayor convergencia social en Europa. Se basan en los principios de solidaridad y responsabilidad, primacía de la persona y de los objetivos sociales del capital, y de la

34 http://eur-lex.europa.eu/legal-content/ES/TXT/PDF/?uri=CELEX:52015IE206 $0 \&$ from $=\mathrm{ES}$ 
promoción de la responsabilidad social, la cohesión social y la integración social. Las empresas sociales pueden actuar como motores del cambio social ofreciendo soluciones innovadoras, promoviendo mercados de trabajo integradores y servicios sociales accesibles para todos. Por lo tanto, contribuyen de forma valiosa al logro de los objetivos de Europa 2020.

Define a las empresas sociales como aquéllas que tienen como objetivo primordial la consecución de impactos sociales mensurables y positivos en lugar de generar beneficios para sus propietarios, socios y accionistas, y que, entre otros caracteres, ofrece servicios o bienes con un elevado rendimiento social, y/o emplea un método de producción de bienes o servicios que represente su objetivo social, utilizando sus beneficios, en primer lugar, para la consecución de su objetivo primordial, y ha implantado procedimientos y normas predefinidos que regulan cualquier reparto de beneficios a los accionistas y propietarios, con el fin de garantizar que dicho reparto no vaya en detrimento de su objetivo primordial y está gestionada de forma empresarial, transparente y sujeta a rendición de cuentas, en especial, fomentando la participación de los empleados, los clientes o los intere sados afectados por su actividad empresarial.

Así pues, aun tratándose de una especial clase de empresas donde está ausente como objetivo fundamental y exclusivo el logro del beneficio económico, puede, no obstante, servir de indicativo en sus métodos y medios a las empresas ordinarias en lo que de incorporable sea posible para hacer compatible su beneficio con la utilidad y mejora social y el progreso entendido en tal sentido.

-El Consejo de Europa en junio de 2017 hizo suyos los ODS de la Agenda 2030 de la ONU, sobre los cuales da una "Respuesta de la UE a la Agenda 2030 para el Desarrollo Sostenible: un futuro sostenible para Europa" señalando que la UE había desempeñado un papel fundamental en el proceso que condujo a la adopción de la Agenda 2030 para el Desarrollo Sostenible y sus diecisiete objetivos de desarrollo sostenible (ODS), en septiembre de 2015 y manifiestaba su determinación a asumir el liderazgo en su ejecución.

En las conclusiones que adoptaba, se reiteraba el firme compromiso de la UE y de sus Estados miembros de aplicar plenamente la Agenda 2030 y realizar sus diecisiete objetivos de desarrollo sostenible (ODS). Se exponía la respuesta de la UE a la Agenda 2030 y su planteamiento de cómo ha de aplicarse a escala de la UE. Abarcaba las próximas etapas, los medios y recursos necesarios, la manera en 
que pueden participar las partes interesadas multilaterales y las medidas sobre la supervisión y examen futuros.

Se subrayaba la importancia de lograr, de un modo equilibrado e integrado, un desarrollo sostenible en las tres dimensiones (económica, social y medioambiental) subrayando que es fundamental que el desarrollo sostenible se integre en todas las políticas, y que la UE sea ambiciosa en las que aplica para afrontar los retos mundiales.

El Consejo instaba a la Comisión a establecer, de aquí a mediados de 2018, una estrategia de aplicación que incluya un calendario, objetivos y medidas concretas para aplicar la Agenda 2030 en todas las políticas de la UE. Manifestaba entonces que la Comisión también debería señalar, a más tardar, a mediados de 2018, las deficiencias sobre las que la UE debe hacer un mayor esfuerzo de aquí a 2030 por lo que respecta a la política, la legislación, las estructuras de gobernanza para la coherencia horizontal y la ejecución.

La UE pedía a los demás Estados miembros de las Naciones Unidas y a todas las partes interesadas, incluidos la sociedad civil y el sector privado, que contribuyesen a la aplicación de la Agenda 2030 con respecto de la cual decía que se debe hacer un mayor esfuerzo para promoverla. En sus Conclusiones, el Consejo hizo hincapié en la falta de compromiso público e instaba a que se adoptasen medidas para concienciar a los ciudadanos de la UE al respecto.

- También dicho Consejo, en su reunión del 10 de diciembre de 2019, adoptó unas Conclusiones sobre la aplicación por la UE de la Agenda 2030 de las Naciones Unidas para el Desarrollo Sostenible y sus 17 Objetivos de Desarrollo Sostenible (ODS). En ellas señala que La Agenda y sus Objetivos se consideran fundamentales para poner fin a la pobreza y garantizar que las generaciones actuales y futuras vivan de forma pacífica, saludable y segura. Se recalca la necesidad de agilizar las actuaciones tanto dentro de la UE como en otras partes del mundo para cumplir el propósito y alcanzar los objetivos de la Agenda 2030. Asimismo se reafirma que la UE y sus Estados miembros seguirán ejerciendo el liderazgo en la aplicación de los ODS, apoyando al mismo tiempo un multilateralismo efectivo y un orden internacional basado en normas.

Acoge positivamente la edición de 2019 del "Informe de seguimiento sobre los avances hacia la consecución de los ODS en el contexto de la UE" de Eurostat, que dice que constituye un documento crucial para medir los avances de la UE hacia la consecución de los 
ODS y anima a los Estados miembros a que eleven el nivel de aspiración de sus respuestas nacionales y a que integren de forma proactiva la Agenda 2030 en los instrumentos de planificación, las políticas, las estrategias y los marcos financieros nacionales. Recuerda, en fin, sus Conclusiones de junio de 2017 e insta a la Comisión a elaborar una estrategia de aplicación global que esboce calendarios, objetivos y medidas concretas que reflejen la Agenda 2030 y a integrar los ODS en todas las políticas internas y externas pertinentes de la UE.

En España, la referencia y regulación normativa de cuanto se relaciona con la sostenibilidad la tenemos, fundamentalmente, en la varias veces mencionada Ley de Economía Sostenible de 2011 (reformada y actualizada por última vez por la Ley 39/2015, de 1 de octubre, del Procedimiento Administrativo Común de las Administraciones Públicas, que deroga varios de sus preceptos), que tiene por objeto introducir las reformas estructurales necesarias para crear las condiciones que favorezcan un desarrollo económico sostenible, entendiendo por "economía sostenible" un patrón de crecimiento que concilie el citado desarrollo económico, el social y el ambiental en una economía productiva y competitiva, que favorezca el empleo de calidad, la igualdad de oportunidades y la cohesión social, y que garantice el respeto ambiental y el uso racional de los recursos naturales, de forma que permita satisfacer las necesidades de las generaciones presentes sin comprometer las posibilidades de las generaciones futuras.

En consecuencia, y aunque mencione en diferentes ocasiones la RSC, alude a ella en función de la propia sostenibilidad, es decir, desde un punto de vista coadyuvante de la misma, no con la autonomía que le es propia en virtud de su origen ético, buscando, según su propio texto, dar cauce a "muchos de los cambios que, con rango de ley, son necesarios para incentivar y acelerar el desarrollo de una economía más competitiva, más innovadora, capaz tanto de renovar los sectores productivos tradicionales como de abrirse decididamente a las nuevas actividades demandantes de empleos estables y de calidad", exponiendo también su preámbulo que La Ley se estructura en un Título preliminar, donde se define su objeto, el concepto de economía sostenible y los principios resultantes de actuación de los poderes públicos, y en cuatro Títulos que contienen el conjunto de reformas de impulso de la sostenibilidad de la economía española.

- El primero de ellos se centra en la mejora del entorno económico, entendiendo por tal las actuaciones del sector público que determinan el contexto de desarrollo de la economía. 
- El Título II introduce una serie de novedades directamente vinculadas con el impulso de la competitividad del modelo económico español, eliminando obstáculos administrativos y tributarios, actuando específicamente sobre tres ejes de mejora de la competitividad de las empresas españolas: el desarrollo de la sociedad de la información, un nuevo marco de relación con el sistema de $\mathrm{I}+\mathrm{D}+\mathrm{i}$ y una importante reforma del sistema de formación profesional, que se lleva a cabo mediante esta Ley y una Ley Orgánica complementaria, que efectúa las modificaciones de carácter orgánico necesarias en las disposiciones vigentes.

- El Título III contiene una serie de reformas que, desde la sostenibilidad medioambiental, inciden en los ámbitos centrales del modelo económico: la sostenibilidad del modelo energético, la reducción de emisiones, el transporte y movilidad sostenible, y, especialmente relevante en el caso español, el impulso del sector de la vivienda desde la perspectiva de la rehabilitación. $\mathrm{Al}$ margen del contenido de la Ley quedan las reformas correspondientes a la sostenibilidad social, esencialmente en materia de empleo y de seguridad social, pues las exigencias específicas de acuerdo en estos ámbitos, en el marco del Diálogo Social y del Pacto de Toledo, respectivamente, aconsejan tramitar las propuestas en textos y procedimientos diferenciados.

- El Título IV, finalmente, contiene los instrumentos para la aplicación y evaluación de la Ley de Economía Sostenible.

La Ley tiene veinte disposiciones adicionales, nueve transitorias, sesenta finales y una disposición derogatoria, cabiendo reseñar ahora, tras haberlo hecho ya inicialmente con su art 39, sus tres primeros artículos, relativos (1) a su objeto (introducir en el ordenamiento jurídico las reformas estructurales necesarias para crear condiciones que favorezcan un desarrollo económico sostenible), a la definición de economía sostenible (2) que se concibe como "un patrón de crecimiento que concilie el desarrollo económico, social y ambiental en una economía productiva y competitiva, que favorezca el empleo de calidad, la igualdad de oportunidades y la cohesión social, y que garantice el respeto ambiental y el uso racional de los recursos naturales, de forma que permita satisfacer las necesidades de las generaciones presentes sin comprometer las posibilidades de las generaciones futuras para atender sus propias necesidades", y (3) a sus principios, que relaciona en número de nueve, referentes a competitividad, estabilidad de las finanzas públicas, racionalización de las AAPP, fomento de la capacidad innovadora de las empresas, aho- 
rro y eficiencia energéticas, energías limpias y cuanto se refiere a medio ambiente, racionalización de la construcción residencial, extensión y mejora de la calidad de la educación e impulso de la formación continua como instrumentos de cohesión social y desarrollo personal de los ciudadanos y fortalecimiento y garantía del Estado social, de modo que parece claro que los más estrechamente vinculados con la responsabilidad social son los dos últimos.

Es en el precitado artículo 39 donde desde el enunciado de su título ("Promoción de la responsabilidad social de las empresas" dentro del Capítulo VI dedicado a la Responsabilidad Social de las Empresas) y a lo largo de su texto se hace mención explícita a la Responsabilidad Social (por cuatro veces) y a la Responsabilidad Social Empresarial o Responsabilidad Social de las Empresas al referirse al Consejo Estatal de la Responsabilidad Social Empresarial (constituído por RD 221/2008, de 15 de febrero) y sus objetivos referentes a transparencia en la gestión, buen gobierno corporativo, compromiso con lo local y el medioambiente, respeto a los derechos humanos, mejora de las relaciones laborales, promoción de la integración de la mujer, de la igualdad efectiva entre mujeres y hombres, de la igualdad de oportunidades y accesibilidad universal de las personas con discapacidad y del consumo sostenible, lo que constituye un contenido auténtico de tal clase de responsabilidad.

La regulación legal, pues, constituye una cierta mixtura de conceptos donde la RSC propiamente dicha tiene reservado un espacio reducido de principios aglutinados sin más proyección, aunque, al menos, dentro ya de la legalidad ordinaria y con alguna manifestación más específica en ámbitos como el de los mercados financieros (la transparencia y gobierno corporativo de los arts 27 y ss, o la transparencia de los mercados de seguros y fondos de pensiones del art 30 y la transparencia e información a los consumidores en materia medioambiental del art 83).

\section{CONCLUSIONES}

En conclusión, podemos decir que se aprecia y hemos de defender un proceso de simbiosis, de interacción que culmine en fusión, entre conceptos como derechos humanos, transparencia, diligencia, igualdad de trato, códigos éticos, gobernanza, comercio justo, información, etc (RSC/RSO), con otros como respeto del medio ambiente, freno al cambio climático, competitividad, digitalización, etc (SC/SS) en lo que será probablemente de futuro la Responsabilidad 
Social, sin más adjetivaciones, aunque siempre el ámbito empresarial tenga un perfil hasta cierto punto diferenciado. Se está, pues, en un estadio de evolución de la RSC y la SC hacia la RS.

RS es un término que, según se predijo, significa compromiso, y más en concreto, el que tienen los individuos como tales o como miembros de un colectivo consigo mismos y con la sociedad directa o indirectamente. Cabe precisar, no obstante, que constituye un valor que progresa escalonadamente, toda vez que se ha de trascender de ser individuos responsables a profesionales (gobernantes, empresarios, directivos y trabajadores) responsables y de ahí a sociedades responsables en todos los ámbitos posibles para beneficio de un auténtico progreso en la propia condición humana, al margen de interpretaciones sesgadas del concepto.

Como ya ha habido ocasión de manifestar ${ }^{35}$, no se trata de ninguna utopía, pero incluso si así se entendiese, no es posible olvidar que la Humanidad ha evolucionado y avanzado gracias a lo que en su momento se consideraba como tal en el sentido peyorativo de la palabra, a pesar de lo cual ha sido lo "utópico" lo que ha permitido abolir la esclavitud, universalizar el voto, reconocer el derecho de huelga, dar lugar a la seguridad social o proclamar la igualdad entre mujer y hombre, sin que pueda prevalecer discriminación alguna, todo lo cual fue en su momento impensable.

Y ahora se está en un momento más idóneo que en cualquiera de todos ellos porque no se trata de progresar sino, simplemente, de sobrevivir, al estar actualmente abocados (casi) irremediablemente a la desaparición, al menos de los modos de vida presentes si no de la vida misma, por lo que, siquiera sea excepcionalmente, se imponen en los diferentes ámbitos medidas radicales al respecto.

Son muchos, sin embargo, los obstáculos que un sector de la propia sociedad de la tecnología, de la telemática y los viajes espaciales, orientada ya al definitivo salto al universo, ha potenciado utilizando también negativamente los medios existentes al alcance de todos, como las redes sociales, y empleando recursos de la mala fe más evidente e interesada, como las new fakes, la desinformación de cualquier otra clase o las proclamas y consignas teledirigidas, sosteniendo, entre otros, el negacionismo activo de los riesgos y cataclismos más evidentes (cambio climático, desastres más o menos naturales, epidemias, etc). Y ello apoyándose precisamente en la difusión inmediata y global de sus tesis y postulados, que se resumen en la

35 Luelmo Millán, M. A., "La Responsabilidad.....” obra citada 
calculada exigencia de lo imposible ${ }^{36}$, con eco gracias a la abundante falta de formación y auténtico conocimiento de la dimensión humana y a la insatisfacción y frustración propia de las crisis pero también, en mayor o menor grado, como estado permanente de cosas y caldo de cultivo del cambio a ninguna parte y, en fin, con base, en buena manera, en oscuros intereses, cuando no en la simple tendencia autodestructiva de nuestra propia idiosincrasia.

De ahí los movimientos "espontáneos" en pro de una libertad absoluta sin límites ni obligaciones, sin responsabilidad, pero muy consciente de"sus"derechos fundamentales, que cursan en una sola dirección, como los medios dan fidedigno testimonio diario, del que se deduce, entre otras cosas, la ausencia integral de respeto a la sociedad en su conjunto, a la convivencia y al medio ambiente, que es el marco de la vida.

También son extremadamente tóxicas las conductas y prácticas de la corrupción, que sólo buscan el lucro en perjuicio de todo y de todos, singularmente de los principios de la Responsabilidad y de la Sostenibilidad Social, incluyendo asimismo nuestro medio ambiente, en el que inciden negativamente muchos negocios concebidos o recibidos y ejecutados desde o con las organizaciones y/o instituciones con un completo daño estructural, y, en fin, la ausencia de auténtica y efectiva solidaridad (concepto formalmente sobreutilizado e infrapracticado) entre gentes, territorios y países.

La demagogia en sus diferentes versiones no es extraña en esta materia y hace un gran daño por su poder desinformador y desorientador, y aunque son muchas, como se ha visto, las normas, planes y recomendaciones nacionales e internacionales en la materia, los congresos y reuniones, etc, lo cierto es que, en buena manera, nos perdemos en ellos y no se atisba claramente un progreso real a la velocidad que la situación exige por las trabas e impedimentos de todo tipo como los ya mencionados y algunos más que nos acechan en cualquier recodo del camino y para muchos de los cuales unas organizaciones inter y supranacionales con más poder, con auténticas cesiones de soberanía en algunas materias y sin vetos reservados y excluyentes, constituirían una parte de la fórmula, que se resume en tomar conciencia de tener conciencia a nivel individual y colectivo.

En el específico ámbito del trabajo, en fin, la competencia, con ser el más importante factor de estimulación de la productividad y, por tanto, del negocio y del trabajo mismo, que retribuye a la gran

36 como ácrata conexión con los lemas de algunas experiencias históricas, como la del mayo francés del 68 y su "sé realista y pide lo imposible". 
mayoría de la ciudadanía y le proporciona su medio de vida, aun siendo intrínsecamente libre en una sociedad inspirada en principios democráticos, nunca debe ser salvaje, lo que impone vigilar con eficacia interna e internacionalmente en tal sentido los mercados, informando, en su caso, puntual, íntegra y verazmente a la opinión pública $^{37}$ y ha de encauzarse de modo igualmente racional con exigencias y controles de calidad no sólo para el producto sino también para los sistemas y los medios empleados y con un trato digno para el ser humano, a fin de que el beneficio resultante sea igualmente justo.

Ya se ha dicho que el mundo agoniza ${ }^{38}$. Y nosotros con él si no ponemos un remedio inmediato tras una indispensable, urgente y global toma de conciencia que todavía está en su fase neonata y en ritmo moroso.

No se trata de catastrofismo ni siquiera derrotismo sino de desapasionada (y horrorizada) observación del día a día. Quizás, hace ya mucho tiempo, el mundo de la ciencia ficción y el de los comics se adelantó modesta pero certeramente con sus previsiones y mensajes al panorama que ahora se contempla pero hay que evitar que tales perspectivas se cumplan y no se haga necesario adoptar la última decisión de esos entrañables personajes de Jor-El y Lara, aunque ésta, por lo menos, significó que la vida y su aventura continuaban a años luz en un nuevo mundo (no tan nuevo para sus habitantes), el mismo que ahora demanda auxilio sin poder contar con ningún superhéroe.

37 Cuando se preguntó a Cleóbulo de Lindos, al igual que a los restantes siete sabios de Grecia, sobre cuál sería, a su juicio, la mejor ciudad, contestó: "aquélla en la que los ciudadanos temen más el reproche (social) que a la ley", lo que actualmente tiene, si cabe, mayor significado en un mundo globalizado. Vid. García Gual, C. "Los siete sabios de Grecia (y tres más)", Biblioteca Temática Alianza. Ediciones del Prado, 1995.

38 Para la Secretaria Ejecutiva de Cambio Climático de la ONU, el año 2021 supone una oportunidad "sin precedentes" para hacer un progreso significativo en la lucha contra el cambio climático y urge a "todas las naciones" a construir un futuro tras el COVID-19, economías más sostenibles y más resistentes contra el cambio climático. Por su parte, la Directora Ejecutiva de la Red de Acción por el Clima, ha destacado que el informe de síntesis de la NDC de 26/02/2021 muestra con "cifras muy claras" cómo los gobiernos no consiguen detener la crisis climática. En la misma línea, la Directora Ejecutiva de Greenpeace International, considera que el informe de síntesis de la Secretaría de Cambio climático de la ONU dice una cosa "clara" y es que en este momento el Acuerdo de París está fracasando. "Nos dirigimos hacia una catástrofe climática. Los gobiernos deben trabajar juntos para dar prioridad a las personas y al planeta sobre los intereses de los combustibles fósiles", ha insistido. madripress.com, artículo ya citado. 